\title{
Evaluation of Seasonal Variability of First-order Ionospheric Delay Correction at L5 and S1 Frequencies Using Dual-frequency Navic System
}

Sharat chandra Bhardwaj ( $\sim$ bhardwaj.sharat@gmail.com )

Graphic Era Deemed to be University https://orcid.org/0000-0002-8406-6378

Anurag Vidyarthi

Graphic Era Deemed to be University

Bhajan Singh Jassal

Graphic Era Deemed to be University

Ashish kumar Shukla

Space Application Center ISRO

\section{Research Article}

Keywords: First-Order lonospheric delay correction, NavIC, Code and Carrier Ranges, STEC, Instrumental Biases

Posted Date: May 27th, 2021

DOI: https://doi.org/10.21203/rs.3.rs-532842/v1

License: (9) This work is licensed under a Creative Commons Attribution 4.0 International License. Read Full License 


\title{
Evaluation of Seasonal Variability of First-Order Ionospheric Delay Correction at L5 and S1 Frequencies Using Dual-Frequency NavIC System
}

\author{
Sharat Chandra Bhardwaj ${ }^{1 *}$, Anurag Vidyarthi ${ }^{1}$, BS Jassal ${ }^{1}$ and AK Shukla ${ }^{2}$ \\ ${ }^{1}$ Propagation Research Lab, Department of Electronics \& Communication Engineering, Graphic Era \\ University, Dehradun, India \\ *bhardwaj.sharat@gmail.com,dr.anuragvidyarthi@ieee.org, bsjassal@yahoo.co.in, \\ *ORCID iD: https://orcid.org/0000-0002-8406-6378 \\ ${ }^{2}$ Space Applications Centre (SAC), Indian Space Research Organization (ISRO), Ahmedabad, \\ ashish@sac.isro.gov.in
}

\begin{abstract}
For the precise positioning application it is important to determine and eliminate the positioning error introduced by various sources such as the ionosphere. To develop a standalone precise navigation system, India has launched the seven satellite constellations of NavIC (Navigation with Indian Constellation) system to provide precision positioning over India and surrounded landmass. Since the ionospheric delay depends on the frequency of the satellite signal and NavIC systems work at different frequencies (L5 and S1) than GPS systems (L1 and L2), it is not possible to use the GPS data-driven study for NavIC based location calculations directly. Thus there is a need for a specialized ionospheric study for NavIC systems. In addition, the ionospheric delay is directly proportional to Slant Total Electron Content (STEC) which is dependent upon diurnal and seasonal solar activity. To achieve accurate positioning facilities, there is also a need for evaluation for seasonal variability of ionospheric delay correction for NavIC receivers.

This paper deals with the STEC estimation; its smoothing, and removal of instrumental biases from STEC. The determined true STEC has been used to determine first-order ionospheric delay at L5 and $\mathrm{S} 1$ frequencies. The delay at $\mathrm{S} 1$ has been found less (2 to $7 \mathrm{~m}$ ) as compared to $\mathrm{L} 5$ (10 to $30 \mathrm{~m})$. Furthermore, the seasonal variability of ionospheric delay has been analyzed using about 19 months of data (from June 2017 to December 2018) and found that the ionospheric delay follows unique seasonal characteristics which can be utilized for delay modeling. It has been also observed that the geostationary satellites of the NavIC system are more appropriate than geosynchronous satellites for ionospheric related studies.
\end{abstract}

Key Words: First-Order Ionospheric delay correction, NavIC, Code and Carrier Ranges, STEC, Instrumental Biases

\section{Declarations}

Funding

This work is supported by the Space Applications Center (SAC), Indian Space Research Organization (ISRO), Ahmedabad, India under NavIC - GAGAN Utilization Program.

\section{Conflicts of interest/Competing interests}

Not applicable

Availability of data and material

According to the undertaking signed with SAC, this data is the property of SAC and hence can not be shared.

\section{Code availability}

According to the undertaking signed with SAC, this data is the property of SAC and hence can not be shared.

\section{Authors' contributions}

Not applicable 


\section{Introduction}

Satellite navigation systems are doing wonders in public as well as military applications. The expected positional accuracy of a satellite navigation system, even if for a single frequency user, is sufficient (in meters) for commercial application [1]; however, the demand for precise positioning services is growing exponentially for airborne navigation (in $\mathrm{cm}$ ) and geodetic applications (in $\mathrm{mm}$ ). There are many factors such as troposphere, earth magnetic field, multipath signal, etc. which causes degradation in positional accuracy [2] but the major positioning error is introduced by Ionosphere [3]. In the earth's atmosphere from 60 to $1000 \mathrm{~km}$, a layer of ionized electrons and ions are present. The ionization process occurs mainly due to solar radiations during the day and recombines at the night. The refractive index of this ionized layer is a function of Total Electron Content (TEC) present in the layer. When the signal transmitted from satellites passes through the ionosphere its speed and direction are altered due to a change in the refractive index of the layer and reaches the receiver with a delay called an ionospheric delay. During a normal diurnal solar activity, the first-order ionospheric delay ranges between 10-20 m but during worse ionospheric conditions it can reach up to $100 \mathrm{~m}$. This delay depends upon the slant total electron content (STEC) along the line between satellite and receiver and the frequency of the transmitted signal [4]. The higher-order errors i.e. second and thirdorder is very small as compared to first-order and thus only first-order ionospheric delay has been considered in this paper.

Earlier U.S.-based GPS was being used for global navigation satellite systems (GNSS) to provide coverage all over the world [5]. At present time other satellite systems such as GLONASS (Soviet Union), Galileo (European Union), BeiDou (China), and QZSS (Japan) have been developed to provide a global as well regional coverage. For non-precision applications over the Indian region, GPS satellites are being used in all weather conditions. However, for civil aviation, whose requirements are up to centimeter-level, GPS satellites alone are failed to meet the expected accuracy due to the availability of single frequency data in the public domain [6]. To meet the demand for better accuracy and integrity of aviation services, a Satellite-Based Augmentation System (SBAS) known as "GPS Aided GEO Augmented Navigation" (GAGAN), was developed by the Indian Space Research Organization (ISRO) in collaboration with the Airports Authority of India (AAI). The correction of propagation delay, present in GPS satellite measurement at L1 $(1575.42 \mathrm{MHz})$ is achieved by modeling a Near Real-Time Grid-Based Ionospheric Delay Model using GPS measurements at L1 and GAGAN measurements at L2 (1227.6 MHz). For each GPS satellite, the SBAS Master Station determines clock and ephemeral correction, and vertical ionospheric delays on every Ionospheric Grid Point (IGP), called grid ionospheric vertical errors (GIVEs) [7]. The vertical ionospheric delay at local Ionospheric Pierce Point (IPP) can be obtained by delays at neighboring IGPs and converted into slant ionospheric delay by using a mapping function. To increase the precision of their location estimates, user navigation systems must apply these delay corrections to their ranges measurements obtained from satellite navigation systems [8]. A comparative study has been conducted by Shukla et al. [9] to determine the impact of ionospheric delay on user location across the Indian region using single and dual-frequency GPS receivers. Using the dual-frequency receiver, an improvement of 1-4 $\mathrm{m}$ in the standard deviation of position error was observed as compared to a single-frequency receiver. The standard error deviation reaches its peak around the summer solstice in June. For the prediction of ionospheric delay over the Indian sub-continent Ratnam [10] evaluated the performance of ionospheric delay models i.e. SHF, MPFM, and MMSE during a geomagnetic storm and found that the MPFM model provides better estimation under severe ionospheric disturbances. In another study, Sivavaraprasad and Ratnam [11] compared different forecast models by considering diurnal, monthly, and seasonal TEC variations. The author found that the ARMA model is more effective (with an accuracy of 82-94\%), in forecasting the ionospheric delay as compared to other models. To validate the findings, GPS-based TEC has been used to calculate the ionospheric delay. Also, the author suggested that for early warning of ionospheric storms in the Indian region the ARMA model would be useful. However, the dependency over GPS signal could play a fatal role in an emergency or war-like situations, that's why, for the development of a standalone precise navigation system. India has launched the seven satellites constellation of the Indian Regional Navigation Satellite (IRNSS), now known as NavIC (Navigation with Indian Constellation) to provide precision positioning over India and surrounded landmass [12][13]. In the NavIC's seven satellite constellation three are in geostationary orbit (GEO) at $32.5^{\circ} \mathrm{E}, 83^{\circ} \mathrm{E}$ and 
$131.5^{\circ} \mathrm{E}$ and four (two in each plane) are in inclined geosynchronous orbit (GSO) (29 ${ }^{\circ}$ ) having their crossing longitudes $55^{\circ} \mathrm{E}$ and $111.75^{\circ} \mathrm{E}$. The NavIC positioning services are transmitted on L5 $(1165.45-1188.45 \mathrm{MHz})$ and $\mathrm{S}(2483.5-2500 \mathrm{MHz})$ band with central frequencies $1176.45 \mathrm{MHz}$ and $2492.028 \mathrm{MHz}$ (S1) respectively [14]. In addition to achieving precise positioning, the constellation of NavIC opens new doors to ionospheric and geodetic studies. The higher operating frequency of NavIC as compared to GPS could have an important role in achieving precise positioning services because one of the major sources of error i.e. Ionosphere is reciprocal of the square of the frequency [15]. Since the ionospheric delay depends on the frequency of the satellite signal and NavIC systems work at different frequencies (L5 and S1) than GPS systems (L1 and L2), it is not possible to use the GPS data-driven study for NavIC based location calculations directly. Thus there is a need for a specialized ionospheric study for NavIC systems.

The first-order ionospheric delay correction using coefficients, produced from regional ionospheric data, was developed for NavIC single-frequency users by Rethika et al. [16]. As compared to corrections given by global ionospheric GPS coefficients, the ionospheric corrections with estimated coefficients are better suited. Desai and Shah [17] also performed a comparative analysis between single frequency models (i.e. GIVE and coefficient-based) and dual-frequency to improve the positional accuracy of the NavIC user. As opposed to the conventional coefficient-based model, both GIVE and dual-frequency techniques were found to perform better. But as done by Shukla et al. [9] using GPS data, the variability of ionospheric delay was not addressed by the author. Furthermore, Mehul V. Desai [18] estimated the ionospheric delay of a single-frequency NavIC user using local Taylor Series Expansion (TSE). Even though the accuracy of the regional TSE model was observed to be similar to the dual-frequency model and greater than GIVE and the coefficient-based model, delay estimation involves complex mathematics. However, these studies lacked in evaluating the monthwise variability of ionospheric delay for the NavIC receivers. To achieve accurate positioning facilities, there is also a need for evaluation for the variability of ionospheric delay correction for NavIC receivers.

The calculation of slant first-order ionospheric delay requires accurate knowledge of TEC along the line between satellite and receiver called Slant TEC (STEC) which is generally estimated from the dual-frequency satellite signal. The estimation of STEC from code and carrier phase measurement eliminates many non-frequency dependent error sources but it is not straightforward. The STEC estimated from dual-frequency code ranges are ambiguous; it includes random fast variations in magnitude due to ionospheric scintillation [19] and signals multipath [20]. Thus the code-derived STEC cannot be directly used for ionospheric delay estimation and precise positioning applications $[4,21]$. However, the STEC derived from carrier phase range measurement is comparatively much smooth but an additional ambiguity that is integer carrier cycle needed to be determined [1],[22] This process of integer carrier cycles requires additional data processing steps which makes the STEC estimation more complex, thus code and carrier phase combined smoothing process is being used for true STEC estimation [23]. The estimated STEC is still contaminated by an error which is called Differential Instrumental Biases (DIBs). This error arises because the signals experience different delays within the satellite and receiver hardware at the two frequencies and also referred to with many names such as differential Hardware Biases, Differential Code Biases (DCBs), Total Group Delay (TGD), etc [24]. The estimation of DIBs are essential to calculation true STEC for ionospheric studies and modeling applications which further can facilitate in achieving required navigation accuracy for aviation and geodetic applications [25]. In related researches, several techniques such as selfcalibration of pseudo-range errors (SCORE), least square, Kalman filter-based, neural network, are discussed, but these works are confined to GPS [22],[26],[27]. For the NavIC system, Kalman filter based estimation is used to estimate differential hardware biases for satellite and receiver using multistation data and modeled vertical delay from Global Ionosphere map (GIM) [28]. However, a significant difference in slant delay, computed from vertical delay using NavIC and GIM measurements has been observed. Another NavIC satellite and receiver DIBs estimation algorithm has been implemented by Krishna and Ratnam [29] with the help of single station GPS TEC measurements. In this work, the modified planar fit model was implemented using GPS data to derive coefficients for modeling the local ionosphere. The dependency on GPS data for modeling the local ionosphere could be a major drawback for the implementation of a standalone positioning system. This limitation is addressed by Bhardwaj et al. [30] and a five-state Kalman filter based algorithm was 
used to determine the satellite and receiver DIBs using single station NavIC data only. In addition, the seasonal variability of biases has been analyzed and was found almost stable except during June 2017 and 2018. Since not much monthly or seasonal changes have been observed in the satellite and receiver DIBs, it suggests that errors introduced by satellite and receiver DIBs in the estimation of TEC could also be estimated by calibrating the satellite and the receiver in terms of DIBs from time to time. This work has been followed in this paper for NavIC satellite and receiver DIBs estimation. Furthermore, the determined true STEC (or simply STEC), at any instant of time is affected by solar radiation, geomagnetic storms, and the lower atmosphere waves. The STEC is also dependent upon on position of receiver (latitude and longitude), the elevation angle of satellite, local diurnal solar position, and seasonal changes. As the ionospheric delay directly determined from the STEC, it inherits the dynamics of STEC. Thus it is needed to evaluate the diurnal and seasonal variability of SID at L5 and S1 frequencies in order to achieve precise positioning and modeling of ionospheric delay for NavIC users.

In this work, the STEC has been estimated from code and carrier phase observables from NavIC satellite which are logged at dual frequency L5 and S1. A smooth diurnal STEC curve has been determined by combining code and carrier phase-derived STEC. By implementing the five-stage Kalman filter, the DIBs are estimated and are removed to determine true STEC. Furthermore, the estimation and investigation of diurnal and seasonal variability of the first-order ionospheric delay have been discussed at L5 and S1 frequencies based on data collected over June 2017 to Dec. 2018 from NavIC satellites. The required theoretical background and data collection have been given in section 2. The estimation of STEC, DIB, SID, and the variability of SID have been discussed in section 3 under the heading of results and discussion. The outcome of the work has been outlined in section 4 .

\section{Ionospheric delay Correction}

In the earth's atmosphere, the ionosphere is a composition of neutral ionized gas, free electrons, ions, and neutral atoms or molecules. The cloud of free electrons behaves as anisotropic for the transmission of radio signals and serves as a refractive medium. The signals from satellite bend and also change their velocity during propagation through the ionosphere because of changes in the refractive index of ionospheric layers, and this phenomenon induces a delay in the arrival of the signals at the receiver. In the range measurement between satellite and receiver, derived from satellite signals, this ionospheric delay introduces a positional error that dilutes the precision of the receiver location. The Appleton-Hartree formula [31] gives the refractive index of the ionosphere. The ionospheric delay correction for a satellite signal is given by the expansion of the refractive index term. The observables from the satellite, in which only the first-order term of refractive index term is considered (neglecting higher-order terms due to negligible effect as compared to first-order), can therefore be written as [32]:

$$
C R_{i}=R+d I_{1 i}+B_{i}
$$

where, $C R_{i}$ is code range in meters, $i=1,2$ are satellite carrier frequencies, $R$ is the slant path distance between the satellite and receiver, $d I_{l}$ is first-order ionospheric delay term, and $B_{i}$ is an additional bias term present in the measurement. As $d I_{I i}$ is the delay in slant path due to ionosphere, it can be referred first-order Slant Ionospheric Delay correction in range measurements. The $d I_{l}$, which is directly proportional to STEC and inversely proportional to the square of the carrier frequency, can be written as [33]:

$$
\begin{gathered}
d I_{1}=40.3 \frac{S T E C}{f_{i}^{2}} \\
\text { or, } d I_{1}=4.4839 \times 10^{-16} \times \lambda_{i}^{2} \times S T E C \text { (meters) }
\end{gathered}
$$

where, $\frac{1}{f^{2}}=\left(\frac{\lambda}{c}\right)^{2} ; \mathrm{c}=299792458 \mathrm{~m} / \mathrm{s} ; \lambda$ is signal wavelength.

At NavIC S1 $(\sim 12.03 \mathrm{~cm})$ and L5 $(\sim 25.48 \mathrm{~cm})$ signal wavelengths the $d I_{1}$ becomes $6.489 \mathrm{~cm}$ and $29.1172 \mathrm{~cm}$ respectively for one STEC unit. However, during severe ionospheric conditions (e.g. geomagnetic storm) the value of STEC can rise 100 to 200 units. In this case, the corresponding delay ranges between 6.5 - 13 meters and 29 - 58 meters at S1 and L5 frequencies respectively. Such conditions are a nightmare for any positioning service and thus modeling of ionospheric delay is 
needed to maintain faithful positional information even during the worst-case scenario. To facilitate the development of ionospheric delay model for NavIC system, the diurnal as well as seasonal variability of $d I_{1}$ have been analyzed in section 3 .

\subsection{STEC and DIB}

As per equation (3) the STEC needed to determine for the calculation of first-order ionospheric delay correction i.e. $d I_{1}$, which is generally estimated from the dual-frequency satellite signal. The difference between dual-frequency code or carrier phase observables gives the STEC. This difference also removes all errors that are not frequency-dependent, such as satellite orbital error, tropospheric delay, multipath delay, and delay due to satellite and receiver clock [20]. The STEC can be estimated from the NavIC code and carrier phase measurements at frequencies L5 and S1[34] as given below,

$$
\begin{array}{r}
\operatorname{STEC}_{\mathrm{CR}}=\left(\mathrm{CR}_{2}-\mathrm{CR}_{1}\right) \times \mathrm{Y}[\mathrm{TECU}] \\
\mathrm{STEC}_{\mathrm{CpR}}=\left(\mathrm{CpR}_{1}-\mathrm{CpR}_{2}\right) \times \mathrm{Y}[\mathrm{TECU}]
\end{array}
$$

where, $\mathrm{STEC}_{\mathrm{CR}}$ and $\mathrm{STEC}_{\mathrm{CpR}}$ are code and carrier phase derived STEC respectively in TECU; 1 TECU is $10^{16}$ electrons $/ \mathrm{m}^{2}, \mathrm{CR}_{1}$ and $\mathrm{CR}_{2}$ are code ranges, and $\mathrm{CpR}_{1}$ and $\mathrm{CpR}_{2}$ are carrier phase ranges at $\mathrm{S} 1$ and $\mathrm{L} 5$ frequencies respectively, $\mathrm{Y}$ is a derived constant (4.4192) at NavIC frequencies.

The STEC derived from the carrier phase is more reliable than STEC derived from the code if the integer ambiguities are correctly resolved [35]. However, in the presence of extreme ionospheric conditions, the technique of ambiguity determination becomes more complicated and less effective [36]. The code range STEC estimates, on the other hand, suffer from noise and multipath and also cannot be used directly. To improve the accuracy of STEC, in this paper, the Hatch filter [8] based smoothing technique is included which uses the strengths of both the $\mathrm{STEC}_{\mathrm{CR}}$ and $\mathrm{STEC}_{\mathrm{CpR}}$. The gap between $\mathrm{STEC}_{\mathrm{CR}}$ and $\mathrm{STEC}_{\mathrm{CpR}}$ is computed for each epoch in this process and averaged to determine a leveling constant. To obtain absolute $\mathrm{STEC}$, this constant is added to $\mathrm{STEC}_{\mathrm{CpR}}$ as given below,

where, $D$ is leveling constant, and

$$
S T E C=S T E C_{C p R}+D
$$

$$
D=\frac{1}{Z} \sum_{j=0}^{Z}\left(S T E C_{C R}^{j}-S T E C_{C p R}^{j}\right)
$$

where, $Z$ is the total number of samples.

Even now, the resultant STEC contains a few minor variations that need to be filtered before further processing. For this reason, a moving average (MA) algorithm (similar to low-pass filtering) has been used in which each data point is obtained by an average value of the neighboring data points within a data span. The data span of the MA filter is a percentage of the total number of data points i.e. 0.1 uses $10 \%$ of the total data points [32].

$$
F(i)=\frac{1}{2 K+1}(f(i+K)+f(i+K-1)+\cdots+f(i-K))
$$

where, $F(i)$ is the filtered output, $K$ is the number of neighboring data points on each side of $f(i)$, Here span of the filter is $2 K+1$.

As discussed in section 1, the satellite and receiver DIBs are introduced due to taking the difference of measurements at dual frequencies. Thus the determined STEC is still corrupted with the satellite and receiver DIBs and is represented as $\mathrm{STEC}_{\mathrm{b}}$ in the following text. The DIBs can be determined by implementing a five-state Kalman filter in which three are for Vertical TEC (VTEC) modeling at IPP and two are for DIBs. The Kalman filter is a computational algorithm that, based on previous estimates and current measurements, optimally estimates the current system states. The formulation of expression for the Kalman filter is given below in which $\mathrm{STEC}_{\mathrm{b}}$ is the current measurement input [30]:

$$
\mathrm{STEC}_{\mathrm{b}}=\left(\mathrm{M}_{\mathrm{f}} * \mathrm{VTEC}\right)+\mathrm{SB}+\mathrm{RB}
$$

where, VTEC is the estimated vertical TEC at IPP, SF is a mapping function $\left(\mathrm{M}_{\mathrm{f}}\right)$ to convert VTEC into STEC; and SB and RB are satellite and receiver DIBs respectively. The $\mathrm{M}_{\mathrm{f}}$ is given as: 


$$
M_{f}=\left[1-\left\{\frac{R_{E} \cos E l}{R_{E}+H_{I P P}}\right\}^{2}\right]^{-\frac{1}{2}}
$$

where, $R_{E}$ is the earth's mean radius (m), El is the elevation angle of satellite (radians), and $H_{I P P}$ is the height of IPP (taken as $350 \mathrm{~km}$ ). The mathematical formulation and implementation steps have been discussed by Bhardwaj et al. [30]. For the implementation of the Kalman filter parameters needed to be initialized. The major parameter such as satellite biases are taken from NavIC data TGD value provided by SAC, Ahmedabad, and the receiver bias has been estimated using Fitted Receiver Bias (FRB) technique [26]. In FRB receiver bias is estimated by applying a range of bias values (b(i), where, $i$ ranges from -30 to $30 \mathrm{~ns}$ ) and finding the one that gives a minimum deviation of VTECs to their mean. Then the total standard deviation is obtained for a given time. The value of $b(i)$ is taken to be an appropriate receiver bias if the sum of the standard deviation is the minimum value.

Over a time interval, the sum of the standard deviation of VTECs for trial bias b(i) is given as,

$$
\Delta_{\mathrm{i}}=\sum_{\mathrm{n}=1}^{\mathrm{N}} \alpha_{\mathrm{i}}(\mathrm{n})
$$

where,

$$
\alpha_{\mathrm{i}}(\mathrm{n})=\sqrt{\frac{1}{\mathrm{M}} \sum_{\mathrm{m}=1}^{\mathrm{M}}\left(\operatorname{VTEC}_{\mathrm{i}}^{\mathrm{m}}(\mathrm{n})-\overline{\mathrm{VTEC}}_{\mathrm{i}}(\mathrm{n})\right)^{2}}
$$

$\mathrm{N}$ is the total number of samples during the desired measurement time interval, and $\mathrm{M}$ is the total number of satellites under observation.

The obtained initial receiver bias receiver is supplied to the Kalman filter and the value of each satellite DIB and receiver DIB can be obtained. By eliminating these DIBs, the true STEC from each satellite can be obtained which is further used for the calculation of corresponding $d I_{1} \mathrm{~s}$. The collection of data and the obtained results are discussed in the next two sections.

\subsection{Data Collection}

The IGS (IRNSS/GPS/SBAS) receiver is installed at Graphic Era University, Dehradun $\left(31.26^{\circ} \mathrm{N}\right.$ and $\left.77.99^{\circ} \mathrm{E}\right)$. The raw binary data of NavIC, GPS, and GAGAN satellites are logged at every second in UTC (Coordinated Universal Time) format. The NavIC satellites (PRN 2 to PRN 7) data are available at dual frequency L5 and S1, whereas, the data of GPS and GAGAN are available at L1 frequency only. The data from PRN 1 is not available due to satellite clock failure. From the raw binary files, satellite data are extracted into CSV (Comma Separated Value) file format using extraction feature in receiver GUI. These data files are imported in MatLab software environment combined to form a 24hour data file at both L5 and S1 frequencies. The combined data is converted from UTC to IST (Indian Standard time) format to facilitate analysis in terms of localized sun position (time of the day). In this work, about 19 months of data, from June 2017 to December 2018 has utilized for the STEC and $d I_{1}$ estimation, and seasonal variability analysis of $d I_{1}$. However, data of few days in almost every month are not included because the measurements from the receiver are either highly disturbed by a severe ionospheric condition or unavailable due to power failure. Thus, the represented data are in a total number of days rather than in a continuous number of days as given in Table 1. Furthermore, the monthly data has been clubbed to form seasonal data i.e. summer (May, June, July, August), winter (November, December, January, February), and equinoctial (March, April, September, October) [37]. In this paper, extracted data have been pre-processed for ambiguities such as missing data, zero or very high values, etc for STEC estimation. The variations of azimuth and elevation angle of NavIC satellites (PRN 2-7) during 24 hours have been plotted in Fig.1. From the figure it can be observed that the variation in azimuth and elevation angles for geostationary (GEO) satellites (PRN 3,6,7) are very small as compared to geosynchronous (GSO) satellites (PRN 2,4,5). All satellites, except PRN 3, are having an elevation angle below $50^{\circ}$ most of the time. 
Table 1 Total number of days in a month considered for analysis during 2017-2018

\begin{tabular}{|c|c|c|c|c|c|c|c|c|c|c|c|c|c|c|c|c|c|c|c|}
\hline Season & \multicolumn{3}{|c|}{ Summer 17} & \multicolumn{2}{|c|}{$\begin{array}{l}\text { Equinoctial } \\
17\end{array}$} & \multicolumn{4}{|c|}{ Winter $17-18$} & \multicolumn{4}{|c|}{ Summer 18} & \multicolumn{4}{|c|}{ Equinoctial 18} & \multicolumn{2}{|c|}{$\begin{array}{l}\text { Winter } \\
18\end{array}$} \\
\hline & 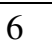 & 7 & 8 & 9 & 10 & & & 1 & & & & & & & $T$ & נה & 0 & 11 & 12 \\
\hline ays & & & & 15 & & & 20 & & 20 & 27 & & & 16 & 0 & 23 & 11 & 11 & 20 & 22 \\
\hline
\end{tabular}

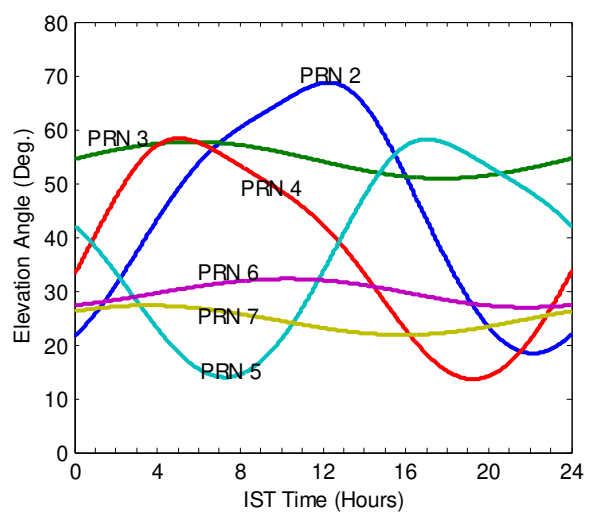

(a)

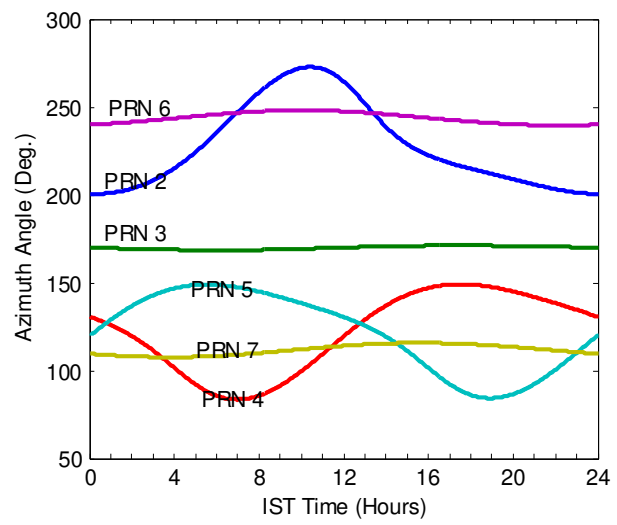

(b)

Fig.1 Diurnal (a) Elevation angle (b) Azimuth angle variation of Satellites PRN 2-7 on Jun. 5, 2017

\section{Results and Discussion}

\subsection{Estimation of STEC}

To achieve ambiguity and noise-free STEC, smoothing techniques are needed as discussed in section 2.1. For each satellite, the leveling constant D that is needed for STEC smoothing using carrier phase (Eq. 6) has been calculated using equation 7, as shown in Fig. 2(a). Here, 200 samples have been taken as $\mathrm{Z}$. There is a change in the $\mathrm{D}$ for satellites for samples $\mathrm{Z}<50$, but no significant change for any satellite has been observed for samples $Z>50$. The $K$ is now taken as 50 for STEC smoothing and the approximate value D for satellites PRN 2 to 7 is 135.83, 123.2, 190.9, 105.8, 203.37, and 93.3 respectively. The smoothing of the STEC is shown in Fig.2 (b) for PRN5, in which the $\mathrm{STEC}_{\mathrm{CpR}}$ was raised with the constant D (105.8 for PRN 5). It can be seen from the figure that the resulting STEC appears as the STEC $_{\mathrm{CR}}$ average. The value of D is considered constant for the whole day; however, it was appropriate to estimate the D again after identification and correction of the carrier phase cycle slip in STEC $_{\mathrm{CpR}}$. Furthermore, the comparison of $0.1,0.2$, and 0.3 span size was performed over a whole day dataset (86400 samples) to find an acceptable MA filer span as given in $\mathrm{Eq}(8)$. The filtered STECs with different span sizes selected are shown in Fig. 3(a). It can be seen in the figure that as the filter span increases, the sharp shift in the filtered curves is reduced. In other words, the rise in span size neglects the curve's minor feature and preserves its overall structure. At 0.1 span, which preserves the major changes, the most closely fitted STEC curve can be found, and therefore it is considered for the MA filtering process. The filtered STECs for geostationary satellites (PRN 3 67) are shown in figure 3(b) and, are further used in DIB estimation as discussed in the next section.
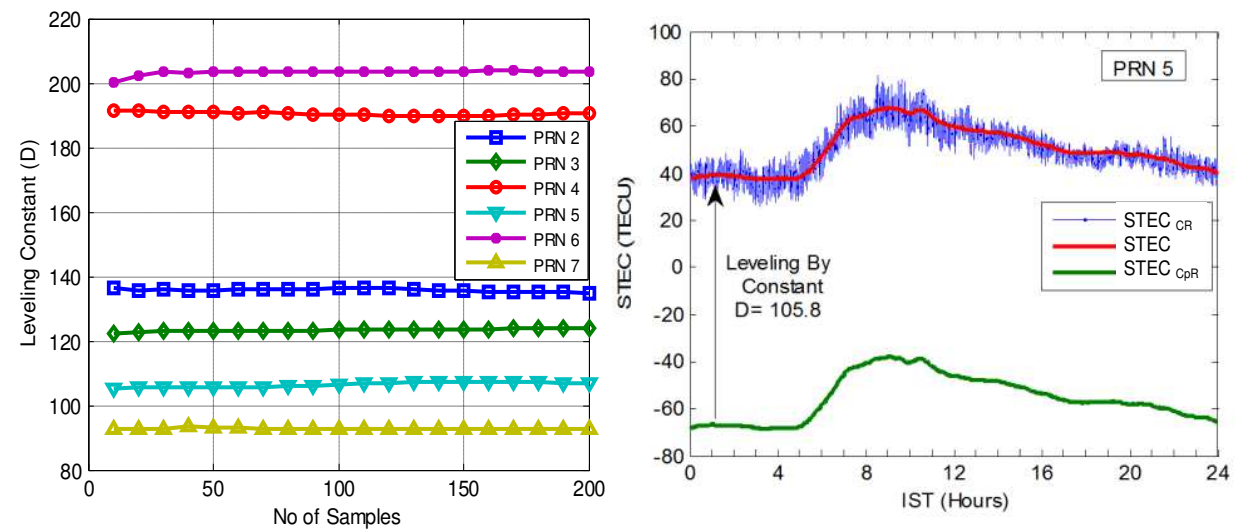

Fig.2 (a) Variation of Leveling Constant (b) Carrier smoothing of STEC measurement 

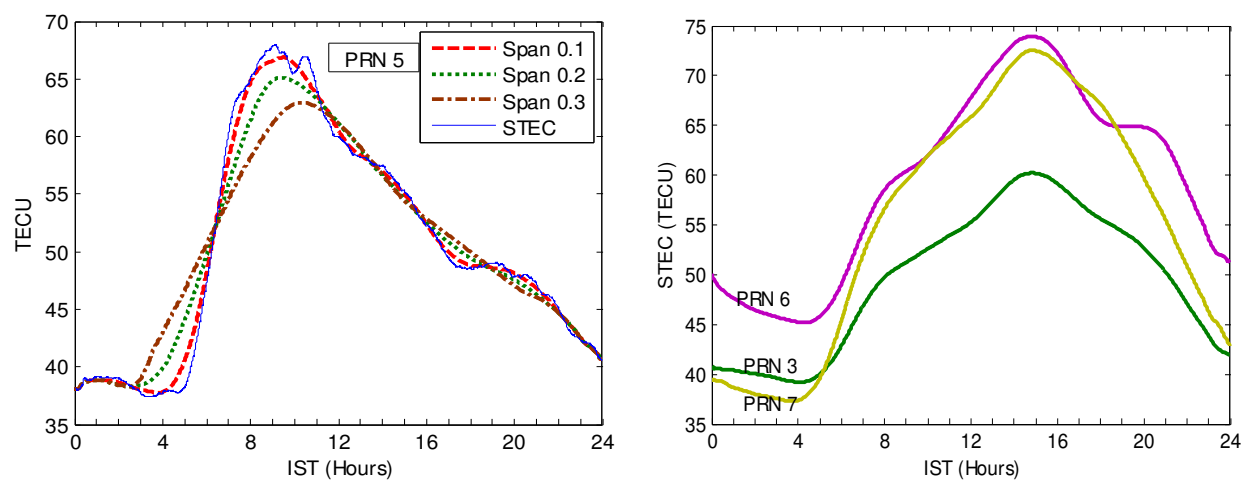

Fig.3 (a) Effect of moving average filter span on STEC smoothing (b) smoothen STEC of PRN 3, 6, and 7

\subsection{Estimation of DIB and true STEC}

It is essential to provide initial satellite and receiver DIBs to begin the operation of the Kalman filter (section 2.1). The initial satellite DIBs were given in Table1 by SAC, Ahmedabad. By applying the fitted receiver bias (FRB) technique, the initial receiver DIB was calculated to be -2.1639 TECU. There is a very small difference between the daily estimated initial receiver DIBs (st. dev. $=0.1744$ ) during a month, so a monthly mean value is used to run the Kalman filter i.e. -1.924997 TECU for June 2017. The calculated $\mathrm{STEC}_{\mathrm{b}}$ using the Kalman filter according to Eq. 9 and the measured STEC are shown in Fig. 4(a). The estimated STEC $_{b}$ converges with measured one within 150 samples at the rate of 1 sample per second. The measured STEC and its filter estimate for the entire day were plotted in Fig. 4(b) to check the efficiency of the Kalman filter. The two curves overlap identically, which indicates that STEC variability can be predicted during the day by the Kalman filter. The Kalman filter however is operated for one hour (00:00 to 01:00) daily for SB RB (DIBs) estimation. The estimated Kalman Filter DIBs are given in Table 2 below. To arrive at a true STEC, these DIBs are omitted from the measured STEC $_{\mathrm{b}}$. For better understanding, the STEC hourly average values are plotted in Fig. 5(a) and curve patterns are found to be identical except for a few days. The mean of these curves is thus plotted with standard deviation in Fig. 5(b) for monthly analysis. The curves display almost similar activity ( \pm 1 TEC) at morning (00:00 to 05:00hrs) and night (20:00 to 24:00), and are within \pm 3 TECU) during the rest of the day. This shows the feasibility of taking a monthly mean of the STEC for further analysis. However, non-averaged STEC values were used to determine the ionospheric correction $\left(d I_{1}\right)$ and are discussed in the following section.

Table 2 Estimated DIB Values using Kalman Filter (June 5, 2017)

\begin{tabular}{|c|c|c|c|}
\hline PRN & Initial SB (TECU) & Estimated SB (TECU) & Estimated RB (TECU) \\
\hline 2 & -12.1042 & -12.1942 & -2.2540 \\
\hline 3 & -10.9155 & -10.8075 & -2.0559 \\
\hline 4 & -8.3399 & -8.4848 & -2.3087 \\
\hline 5 & -18.5607 & -18.6990 & -2.3022 \\
\hline 6 & -11.9332 & -11.4 & -1.6307 \\
\hline 7 & -10.6061 & -10.7728 & -2.3303 \\
\hline \multicolumn{2}{|c|}{ Initial RB = -2.1639 } & Mean RB & -2.1469 \\
\hline
\end{tabular}



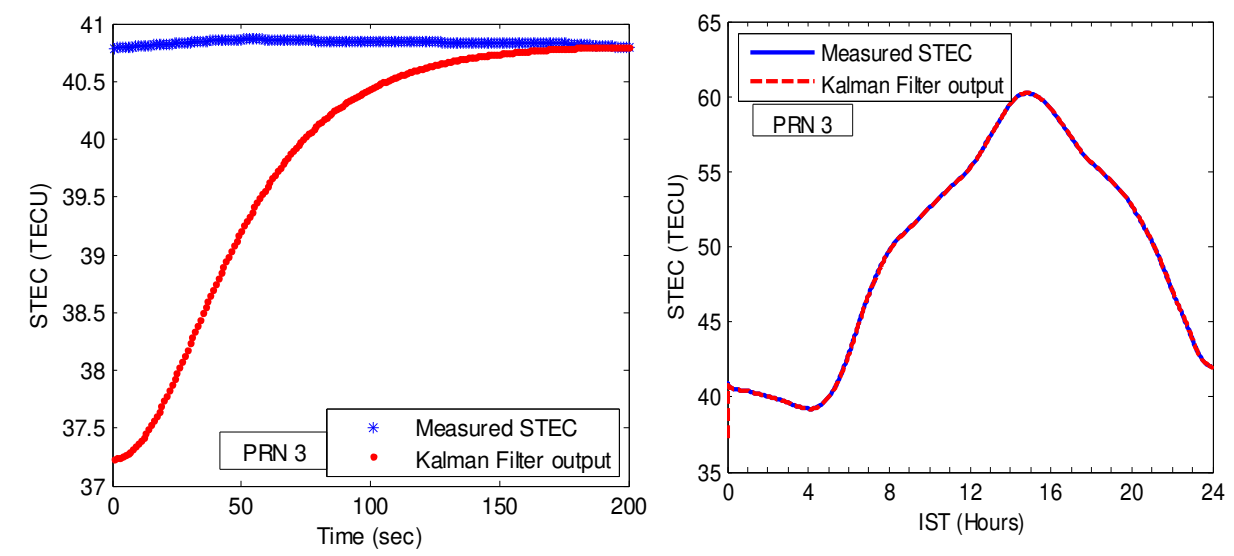

Fig.4 (a) Convergence and (b) Performance of Kalman filter

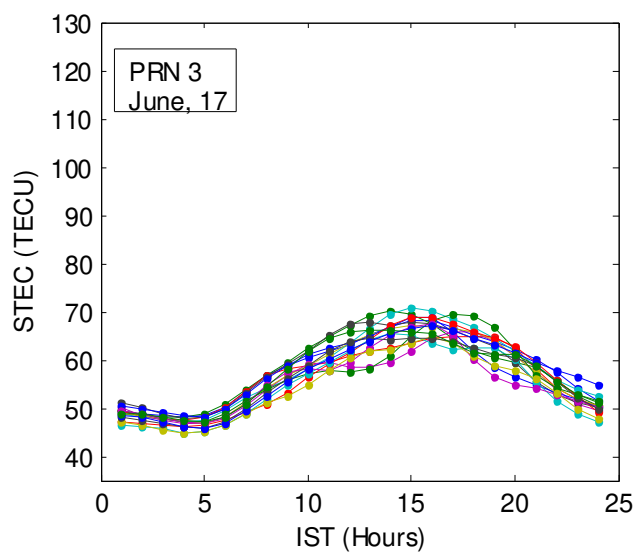

(a)

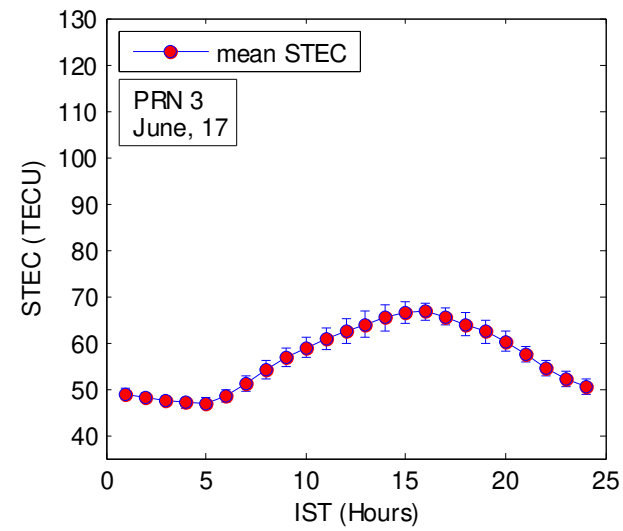

(b)

Fig.5 STEC in June 2017 for PRN 3 (a) Daily temporal variation (b) Mean monthly temporal variation

\subsection{Analysis of First-order Ionospheric correction $\left(d I_{1}\right)$}

The first-order ionospheric correction $\left(d I_{1}\right)$ has been estimated at both the frequencies L5 and S1 using STEC as per Eq. 3. The hourly average value of $d I_{1}$ was calculated at L5 and S1 frequencies for all satellites (PRN 2-7) and separately plotted in Fig.6 (a)-(g) and Fig.7 (a)-(g) respectively for June 2017. As NavIC signal wavelength at S1 frequency is shorter $(\sim 12.03 \mathrm{~cm})$ than $\mathrm{L} 5(\sim 25.48 \mathrm{~cm})$, the value of $d I_{1}$ at $\mathrm{S} 1$ is less $(2$ to $7 \mathrm{~m})$ as compared to $\mathrm{L} 5$ (10 to $\left.30 \mathrm{~m}\right)$. This could be seen as a major benefit of the S1 frequency NavIC system, which has less ionospheric delay over the GPS operating at larger wavelength signals L1 $(19.03 \mathrm{~cm})$ and L2 $(24.63 \mathrm{~cm})$. From the figures, it can be observed that the GSO satellites (PRN 2,4,5) have $d I_{1}$ peaks (at both L5 and S1 frequency) at different hours of the day. This is because along with diurnal solar activity the STEC depends upon the elevation angle and thus the $d I_{1}$ follows the combined pattern. For GSO satellites there a large variation in elevation angle (Fig. 1(a)), and with a decrease in elevation angle the path length between satellite and receiver increases and thus increase in STEC values. In the case of GEO satellites (PRN 3,6,7) the peaks are during the same time duration (15 to $16 \mathrm{hrs}$.) due to small variations in elevation angle as compared to GSOs (PRN 2,4,5) and hence the STEC and $d I_{1}$ curves are mainly following the solar activity. To study the characteristics of the ionospheric variability, plotted curves can be divided mainly into four value zones i.e. minimum before sunrise (0-5 hrs), rise after sunrise and before afternoon (5 - $13 \mathrm{hrs}$ ), peak (13 - $16 \mathrm{hrs})$, and fall (16 - $18 \mathrm{hrs})$. In the minimum zone, the $d I_{1}$ curves at both L5 and S1 frequencies for all satellites reach their minimum just before sunrise (i.e. $5 \mathrm{hrs}$ ) during the entire month as shown in Fig.6 (a)-(f) and Fig.7 (a)-(f) respectively. This verifies the typical ion-recombination process in the ionosphere due to the absence of solar radiation. From the figures, it can be observed that the $d I_{1}$ curves experience a sharp rise after sunrise due to photo-electron generation in the ionosphere and continue to increase with solar radiations. The rising rate, peak hours, and falling-rate of $d I_{1}$ of GEO satellites (Fig.6 and 7 (b), (e) 
and (f)) are found similar, however, the GSO satellites (Fig. 6 and 7 (a), (c), and (d)) are having different rising rates, peak hours, and falling rates due to the combined effect of elevation angle and solar radiations as discussed previously.

From the above discussion, It can be said that the GEO satellites are more appropriate for the study of the ionospheric delay concerning diurnal solar activity than GSO satellites since they have an almost stable constellation in the sky and the ionospheric delay curves obtained $\left(d I_{1}\right)$ mainly follow diurnal solar activity. However, to observe the seasonal characteristics of first-order ionospheric correction the analysis of the $d I_{1}$ curves for all satellites (PRN2-7), at dual-frequency, have been carried out in this work. In Fig. 6 (a-f) and 7 (a-f), it can be observed that the $d I_{1}$ curves of each satellite are having almost identical behavior except for few days, and thus a monthly mean value (similar to STEC) has been calculated and plotted in Fig. 6 and 7 (g-1) for all satellites at L5 and S1 frequencies respectively. Since there is not much variance ( $\max \pm 2 \mathrm{~m}$ at $\mathrm{L} 5$ and $\pm 1 \mathrm{~m}$ at $\mathrm{S} 1)$ in the mean curve, a monthly mean $d I_{1}$ values can be considered for the seasonal analysis. The diurnal variation of monthly mean $d I_{1}$ curves for the summer months, 2017 (June, July, August) are plotted in Fig. 8 at L5 and S1 frequencies for all PRNs. The delay correction curves for the GEO satellites (Fig. 8(b),(e),(f) at L5 and 8 (h),(k),(l) at S1) are having identical behavior during all three months, whereas GEO satellites except PRN 5, (i.e. Fig. 8(a), (c), and (d) at L5, and 8(g), (i), and (j) at S1), are experiencing an early shift and increasing peak values from June to August. However, the other characteristics of curves i.e. minimum zone, rising-rate, and falling-rate are similar for all three months. A seasonal mean can thus be developed to evaluate the overall activity of the year-round first-order ionospheric correction $\left(d I_{1}\right)$. The seasonal analysis of firstorder ionospheric correction from summer 2017 to winter 2018 has been given below.

The seasonal curves are plotted in Fig.9 (a) to (1) for each satellite (PRN 2-7) at dual frequencies L5 and S1. From the figures, it can be observed that the delay correction curves for GEO satellites at the dual frequencies (Fig 9 (b), (e) and (f) and Fig. 9 (h), (k) and (l)) are having similar diurnal behavior i.e. minimum value, peak hours, but different seasonal characteristics, in terms of rising rate, peak values and fall rate can be observed. The corrections are higher due to greater STEC value during summer and equinoctial months than the winter months. Although, in the equinoctial and summer months GEOs are having and similar peak values, a higher nighttime value, and slow falling rate can be observed during summer months that indicate the effect of ion temperature on electron density in the ionosphere. The ion temperature is an important parameter for ionization distribution as it slows down the rate of recombination in the upper ionosphere[38]. A similar finding is reported by Chauhan et.al. [39], for low and mid-latitude regions. The author also presented the variation of TEC data in the correlation with three solar indices i.e. sunspot number (SSN), $10.7 \mathrm{~cm}$ solar flux (F10.7), and EUV flux, and found that solar indices have a high correlation with TEC in summer than equinoctial and low correlation in winter months. However, this effect needs further investigation as nighttime ionospheric disturbance affects the TEC distribution in low and midlatitude regions [40]. Furthermore, from the Fig. 9 (b), (e) and (f), and Fig. 9 (h), (k) and (l) it can also be observed that the curves of one season from two different years e.g. equinoctial 17,18, summer 17,18 and winter 17-18, 18 are following almost same diurnal characteristics. This verifies that the first-order ionospheric correction undergoes a unique seasonal characteristic which must be considered before ionospheric delay modeling.

As discussed previously, due to diurnal change in elevation the GSO satellites (PRN 2,4,5) follow different diurnal characteristics, and thus a variety of seasonal behavior, i.e. rise rate, peak hours, peak values, and fall rate can be observed from Fig. 9 (a), (c) and (d), and Fig. 9 (g), (i) and (j) at L5 and S1 frequencies respectively. However, the unique seasonal behavior of ionosphere delay, i.e. higher value during summer and equinoctial months than winter, similar peak values but higher value and slower falling rate in the night for summer months can be observed from the curves. Also, the seasonal curves of two different years, except equinoctial months, are similar as observed in the case of GEO satellites. Apart from the difference in the magnitude of first-order ionospheric delay correction at L5 and S1, the curves are identical as they are obtained directly from STEC. The maximum and minimum values of the delay correction of all the seasons and satellites at L5 and S1 frequency are summarized in table 3. The minimum ionospheric corrections for all satellites during all seasons are similar i.e. 12.27 to $16.31 \mathrm{~m}$ at L5 and 2.74 to $3.61 \mathrm{~m}$ at S1. However, the maximum value of correction is high during summer (up to $33.02 \mathrm{~m}$ at $\mathrm{L} 5$ and $7.36 \mathrm{~m}$ at $\mathrm{S} 1$ ) and equinoctial months (up to 
$36.16 \mathrm{~m}$ at $\mathrm{L} 5$ and $8.06 \mathrm{~m}$ at $\mathrm{S} 1$ ). The values are lower during the winter months (up to $24 \mathrm{~m}$ at $\mathrm{L} 5$ and 5.2 at S1) than summer and equinoctial months. The maximum value of the delay correction at L5 and $\mathrm{S} 1$ for all the seasons during two years are found in a range of 17.5 to $36.16 \mathrm{~m}$ and 3.62 to $8.06 \mathrm{~m}$ respectively. Moreover, the overall corrections are observed less at S1 than L5 and this verifies the suitability of the NavIC S1 frequency for precise positioning applications as discussed previously.

Table 3 Seasonal maximum and minimum first-order ionospheric correction at L5 and S1 frequencies for all satellites PRN 2 to 7

\begin{tabular}{|c|c|c|c|c|c|c|c|c|c|c|c|c|c|}
\hline \multirow[b]{2}{*}{ Season } & & \multicolumn{6}{|c|}{ First Order Correction at L5 (Meter) } & \multicolumn{6}{|c|}{ First Order Correction at S1(Meter) } \\
\hline & & $\begin{array}{l}\text { PRN } \\
2\end{array}$ & $\begin{array}{c}\text { PRN } \\
3\end{array}$ & \begin{tabular}{|c|} 
PRN \\
4
\end{tabular} & $\begin{array}{c}\text { PRN } \\
5\end{array}$ & $\begin{array}{l}\text { PRN } \\
6\end{array}$ & $\begin{array}{c}\text { PRN } \\
7\end{array}$ & $\begin{array}{c}\text { PRN } \\
2\end{array}$ & $\begin{array}{c}\text { PRN } \\
3\end{array}$ & \begin{tabular}{|c|} 
PRN \\
4
\end{tabular} & $\begin{array}{l}\text { PRN } \\
5\end{array}$ & \begin{tabular}{|l} 
PRN \\
6
\end{tabular} & $\begin{array}{c}\text { PRN } \\
7\end{array}$ \\
\hline \multirow{2}{*}{$\begin{array}{l}\text { Summer } 2017 \\
\text { (Jun, Jul, Aug) }\end{array}$} & Max & 25.75 & 19.42 & 33.03 & 23.21 & 23.97 & 24.48 & 4.87 & 4.33 & 7.36 & 5.17 & 5.34 & 5.46 \\
\hline & Min & 12.62 & 13.23 & 12.86 & 16.21 & 15.02 & 14.24 & 2.81 & 2.95 & 2.87 & 3.61 & 3.34 & 3.17 \\
\hline \multirow{2}{*}{$\begin{array}{c}\text { Winter 2017-18 } \\
\text { (Nov, Dec, Jan, Feb) }\end{array}$} & Max & 20.19 & 17.55 & 21.12 & 24 & 20 & 20.27 & 4.5 & 3.62 & 4.71 & 5.2 & 4.44 & 4.52 \\
\hline & Min & 12.45 & 12.4 & 12.88 & 15.46 & 13.7 & 13.64 & 2.77 & 2.76 & 2.87 & 3.44 & 3.05 & 3.04 \\
\hline \multirow{2}{*}{$\begin{array}{c}\text { Summer } 2018 \\
\text { (May, Jun, July, Aug) }\end{array}$} & Max & 22.82 & 20.45 & 31.5 & 25.25 & 23.94 & 25.64 & 5.09 & 4.56 & 6.46 & 5.63 & 5.34 & 5.71 \\
\hline & Min & 13.05 & 13.59 & 12.88 & 15.52 & 13 & 14 & 2.91 & 3.03 & 2.87 & 3.46 & 3.1 & 3.12 \\
\hline \multirow{2}{*}{$\begin{array}{l}\text { Winter } 2018 \\
\text { (Nov, Dec) }\end{array}$} & Max & 19.6 & 16.55 & 18.32 & 20.75 & 19.53 & 18.67 & 4.37 & 3.69 & 4.08 & 4.62 & 4.35 & 4.16 \\
\hline & Min & 12.29 & 13.63 & 13.01 & 14.85 & 15 & 13.24 & 2.74 & 3.04 & 2.89 & 3.31 & 3.33 & 2.95 \\
\hline \multirow{2}{*}{$\begin{array}{l}\text { Equinox } 2017 \\
\text { (Sep, Oct) }\end{array}$} & Max & 31.84 & 18.91 & 36.16 & 22.44 & 23.78 & 24.15 & 7.09 & 4.21 & 8.06 & 5 & 5.3 & 5.3 \\
\hline & Min & 12.27 & 12.71 & 13.42 & 16.13 & 14.12 & 14.13 & 2.8 & 2.83 & 2.99 & 3.59 & 3.15 & 3.15 \\
\hline \multirow{2}{*}{$\begin{array}{c}\text { Equinox } 2018 \\
\text { (Mar, Apr, Sep, Oct) }\end{array}$} & Max & 24.16 & 19.86 & 30.12 & 35.6 & 24.75 & 26.58 & 5.38 & 4.42 & 6.71 & 7.93 & 5.52 & 5.92 \\
\hline & Min & 13.13 & 12.64 & 13.23 & 15.3 & 14.64 & 13.69 & 2.92 & 2.82 & 2.95 & 3.41 & 3.26 & 3.05 \\
\hline
\end{tabular}

\section{Conclusion}

To achieve precise positioning services from the NavIC system it is essential to determine and remove the ionospheric errors (i.e. $d I_{1}$ ) from range measurements. In this paper, the estimation of STEC, its smoothing, and removal of instrumental biases have been done. Thus obtained true STEC has been used to determine ionospheric delay at L5 and S1 frequencies. From the diurnal curves, it has been observed that the rising rate, peak hours, and falling-rate of $d I_{1}$ of GEO satellites are found similar, however, the GSO satellites are having different behavior due to the combined effect of elevation angle and solar radiations. Thus GEO satellites are more appropriate for the study of the ionospheric delay with diurnal solar activity than GSO satellites. In this work, the analysis of the $d I_{1}$ curves from all satellites (PRN2-7) at dual frequency have been carried out using about 19 months of data (from June 2017 to December 2018) to observe the seasonal characteristics of ionospheric delay. During this period the ionospheric delay curves at dual frequency are having similar diurnal behavior i.e. minimum value, peak hours, however, different seasonal characteristics, in terms of rising rate, peak values, and fall rate can be observed. The ionospheric corrections are higher due to greater STEC values during summer and equinoctial months than the winter months. Although, in the equinoctial and summer months GEOs are having and similar peak values, a higher nighttime value, and slow falling rate can be observed during summer months that indicate the effect of ion temperature on electron density in the ionosphere. Furthermore, the curves of one season from two different years e.g. equinoctial 17,18, summer 17,18, and winter 17-18, 18 are following almost the same diurnal characteristics. This verifies that the first-order ionospheric correction undergoes a unique seasonal characteristic which must be considered before ionospheric delay modeling. The minimum ionospheric corrections for all satellites during all seasons are similar i.e. 12.27 to $16.31 \mathrm{~m}$ at L5 and 2.74 to $3.61 \mathrm{~m}$ at $\mathrm{S} 1$. The maximum correction for all satellites and during all the seasons at L5 and $\mathrm{S} 1$ are found in a range of 17.5 to $36.16 \mathrm{~m}$ and 3.62 to $8.06 \mathrm{~m}$ respectively. The overall corrections are observed less at S1 than L5 and this verifies the suitability of the NavIC S1 frequency for precise positioning applications.

\section{Acknowledgments}

Authors are thankful to SAC, Indian Space Research Organization (ISRO), Ahmedabad, India for providing the necessary funds and NavIC receiver to carry out this research work. According to the undertaking signed with SAC, this data is the property of SAC and hence can not be shared. 


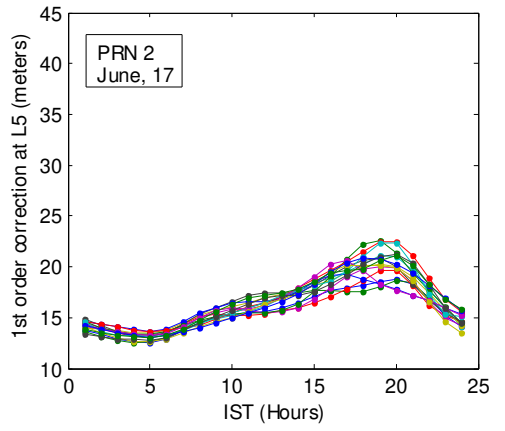

(a)

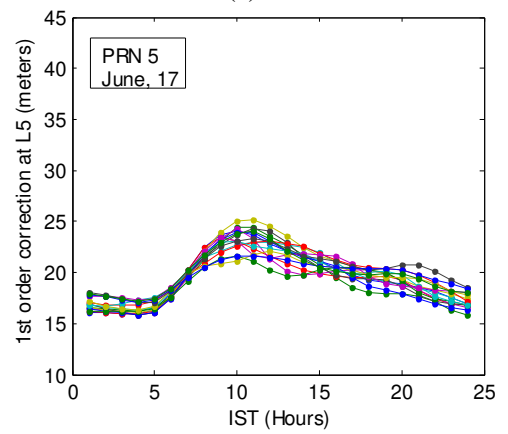

(d)

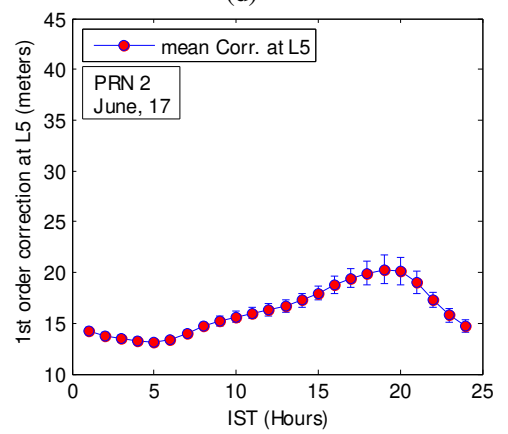

(g)

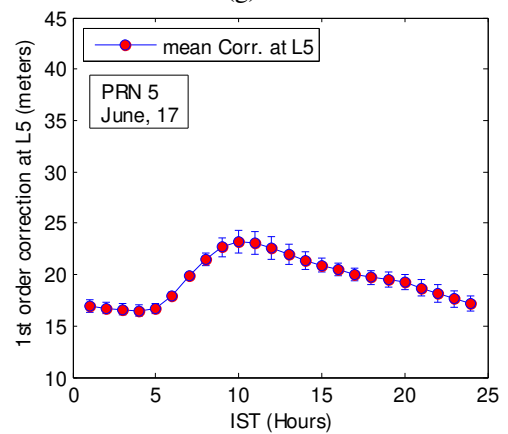

(j)

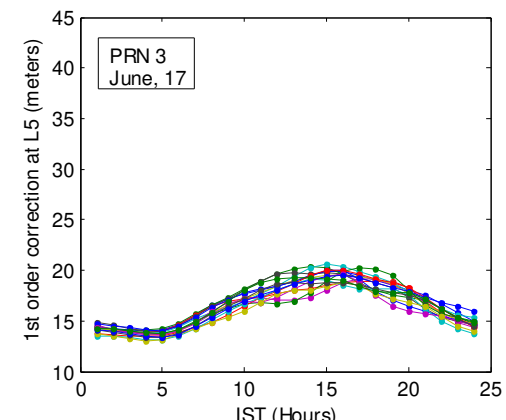

(b)

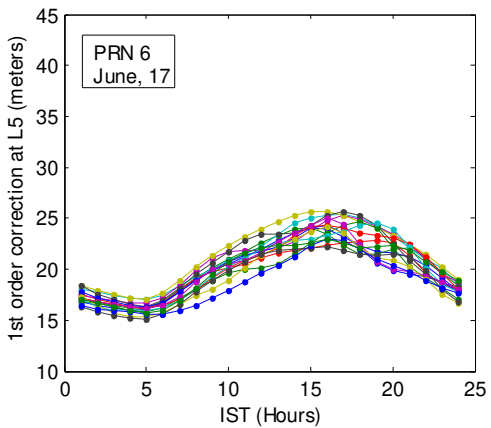

(e)

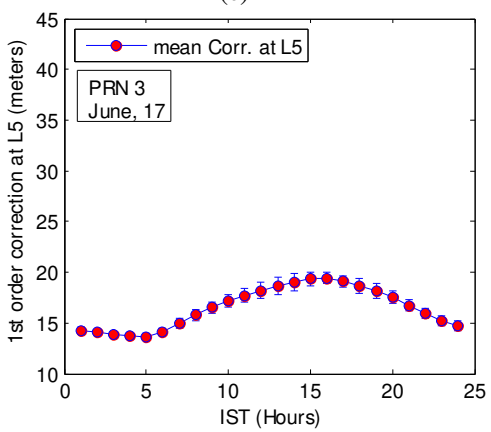

(h)

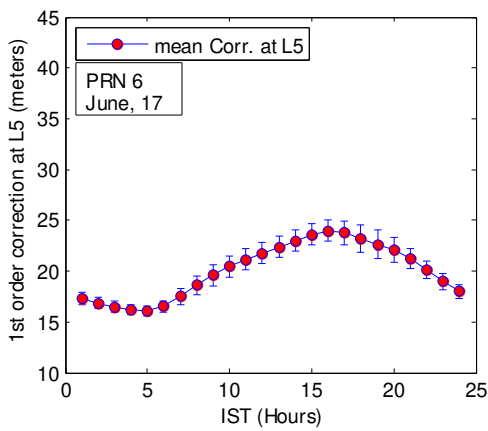

(k)

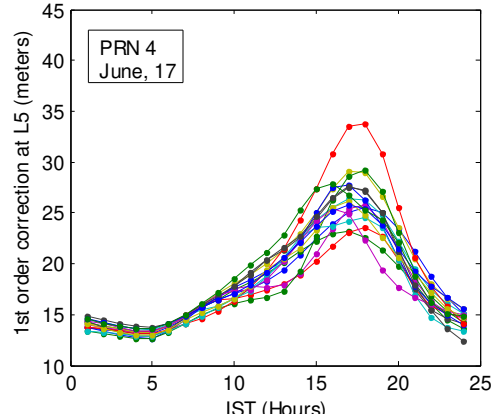

(c)

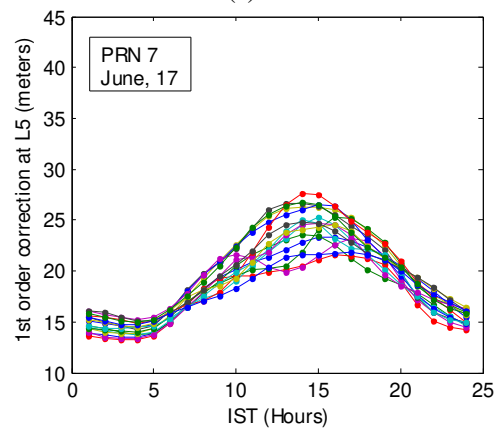

(f)

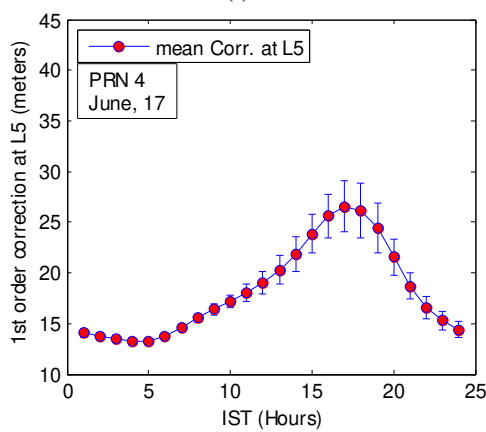

(i)

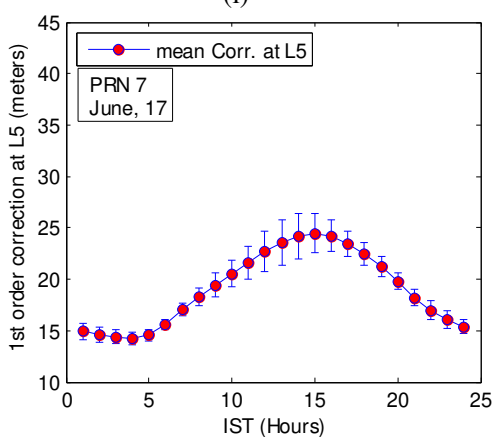

(1)

Fig.6 First order ionospheric correction at L5 (a)-(f) Daily temporal variation, (g)-(n) Mean monthly temporal variation for PRN 2-7 in June 2017

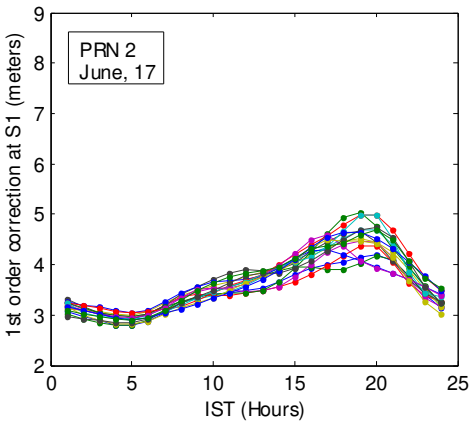

(a)

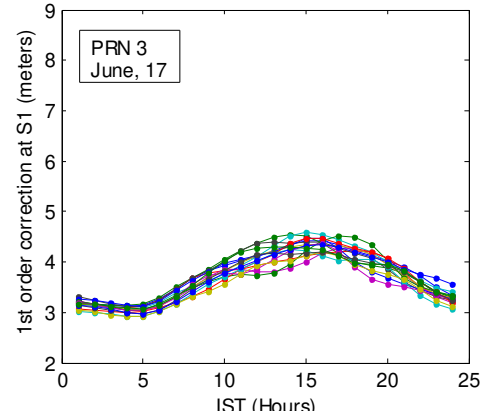

(b)

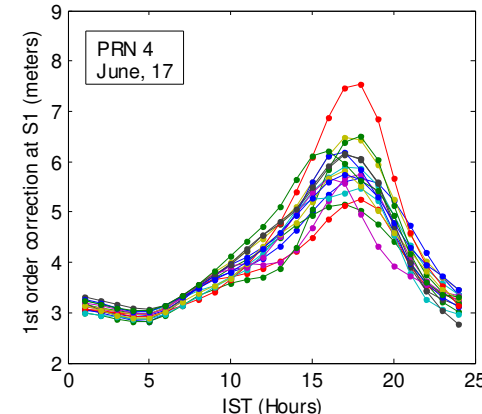

(c) 


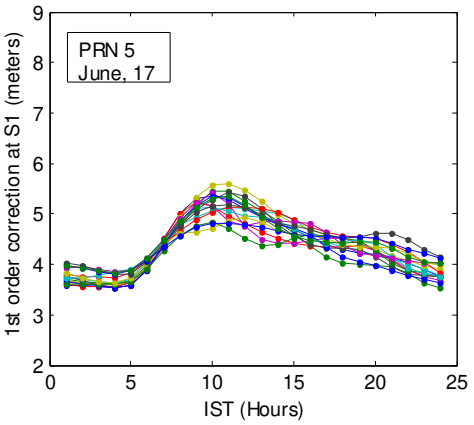

(d)

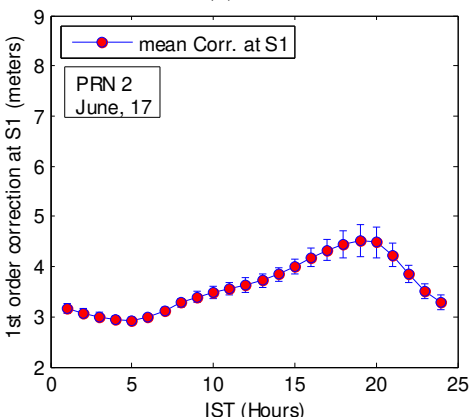

(g)

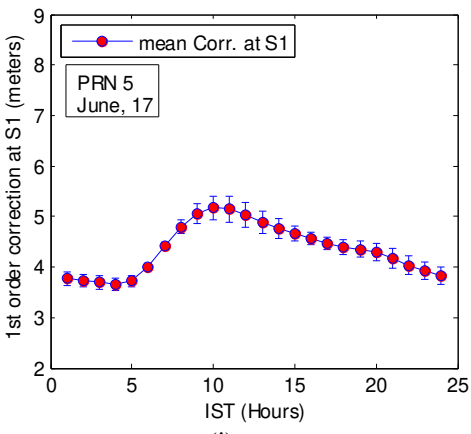

(j)

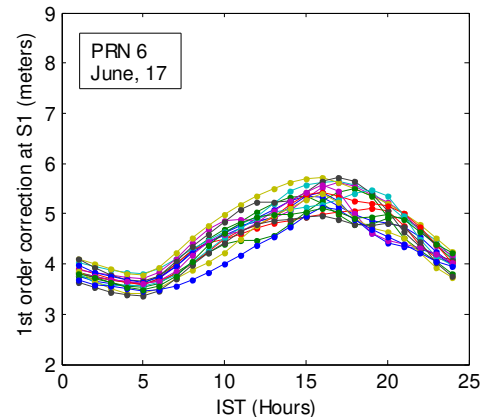

(e)

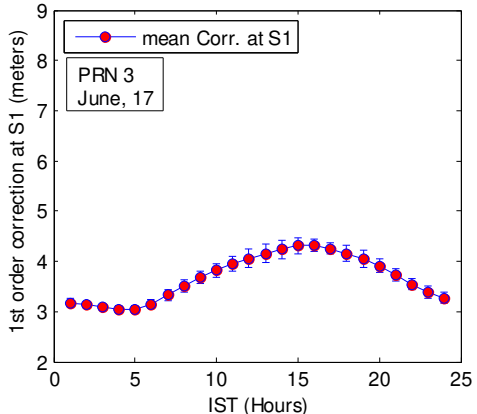

(h)

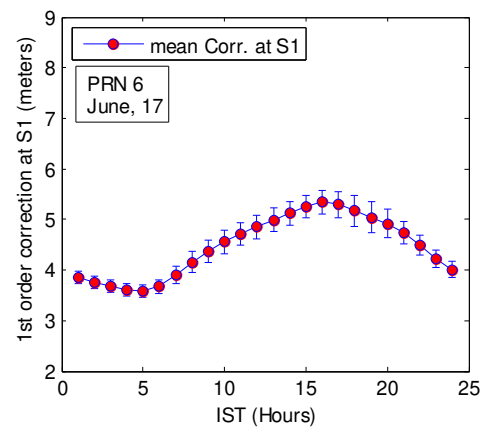

(k)

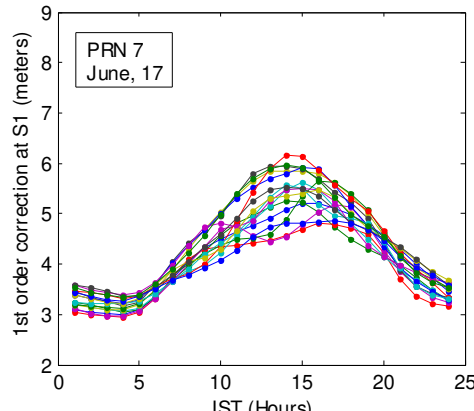

(f)

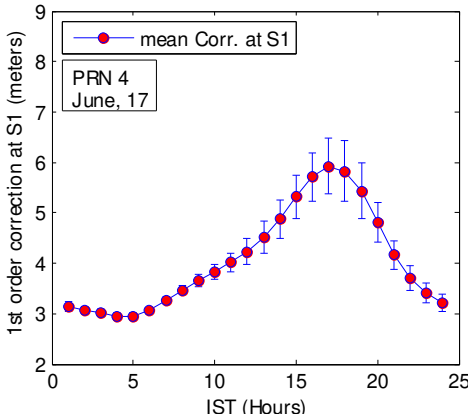

(i)

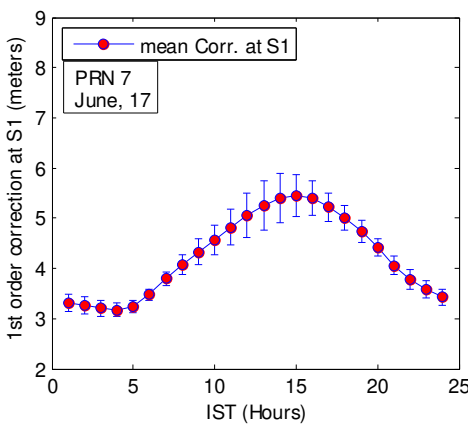

(l)

Fig.7 First order ionospheric correction at S1 (a)-(f) Daily temporal variation, (g)-(1) Monthly mean temporal variation for PRN 2-7 in June 2017

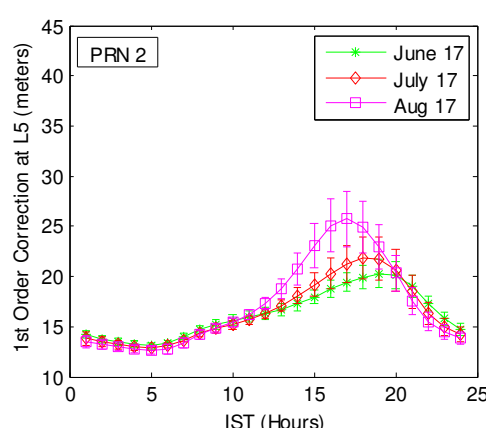

(a)

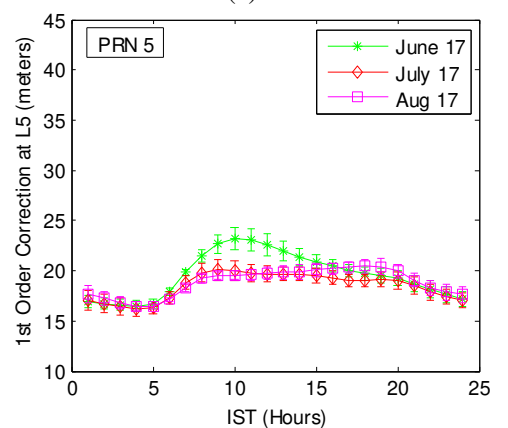

(d)

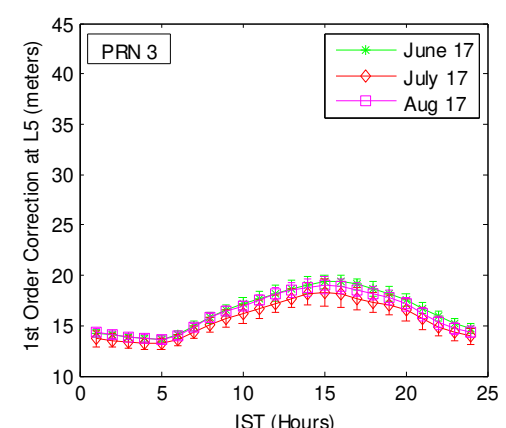

(b)

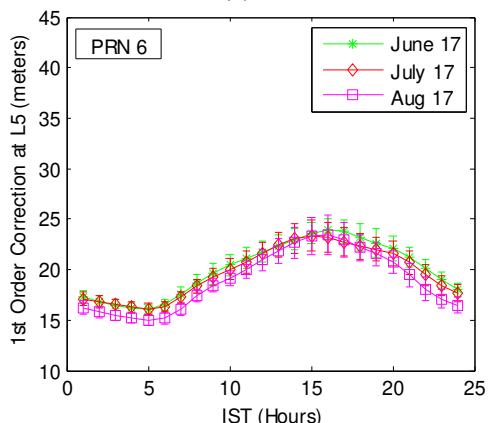

(e)

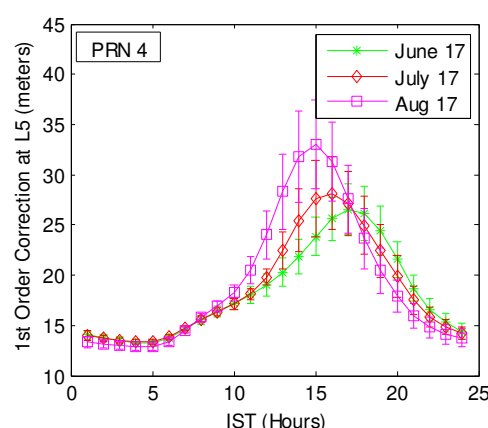

(c)

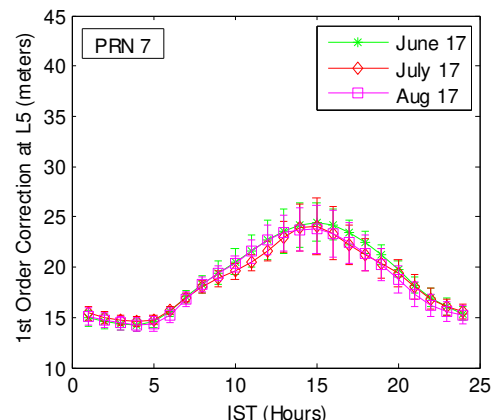

(f) 


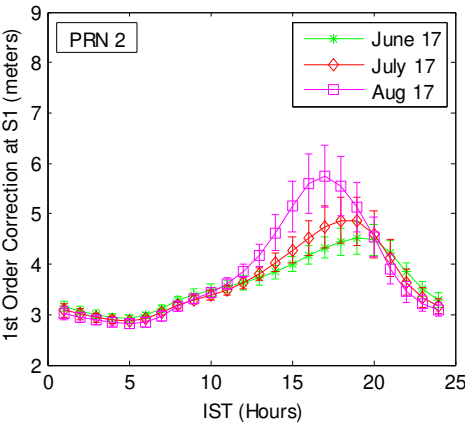

(g)

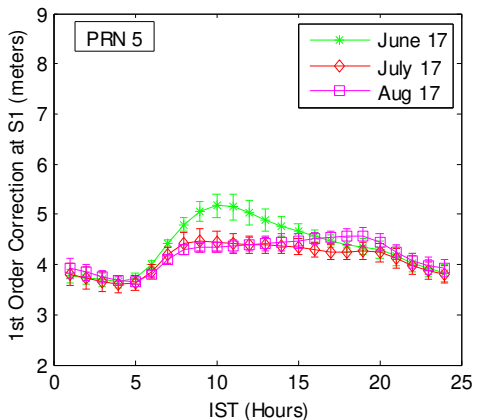

(j)

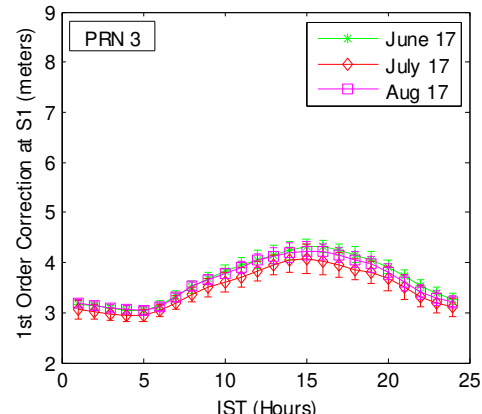

(h)

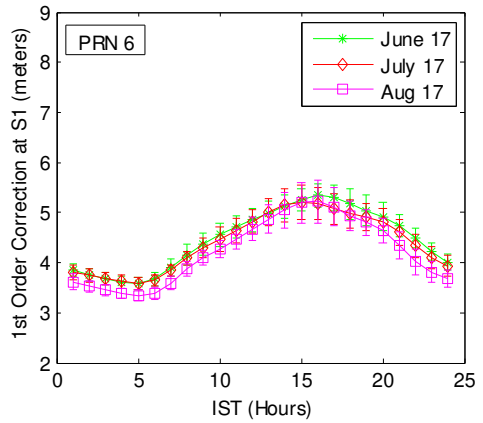

(k)

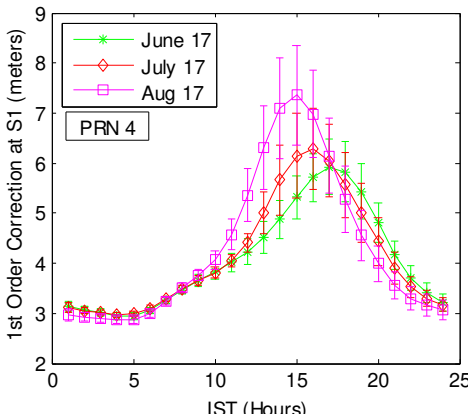

(i)

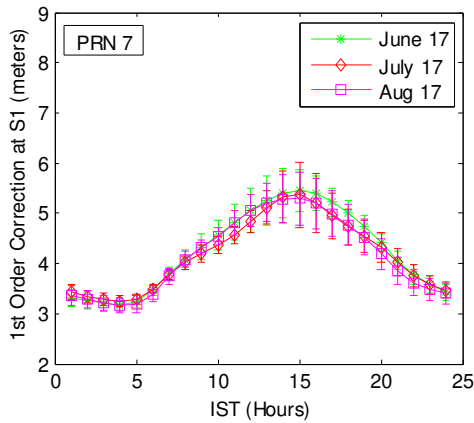

(1)

Fig.8 Monthly Mean temporal variation of first-order ionospheric correction for PRN 2-7 during summer season 2017 (a)-(f) at L5 frequency, (g)-(1) at S1 frequency

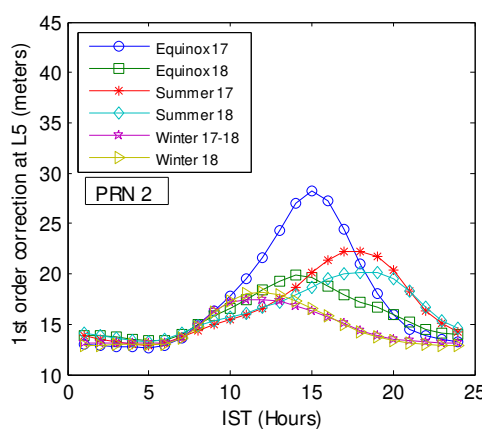

(a)

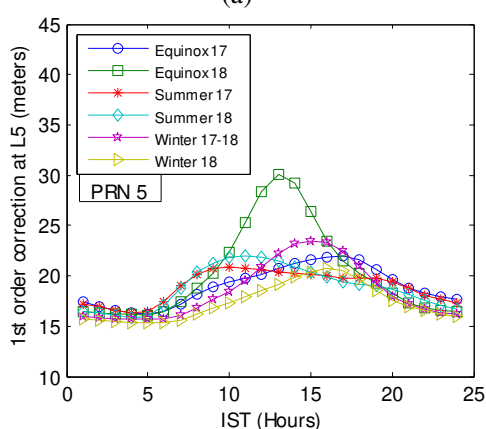

(d)

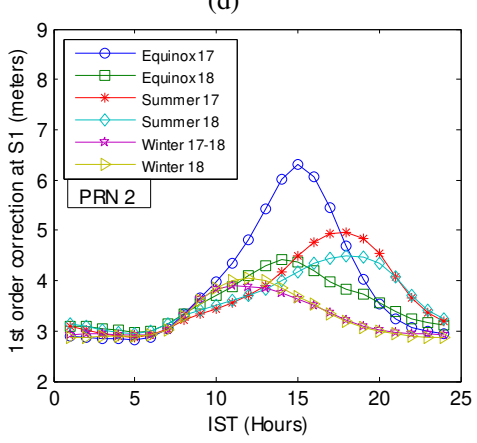

(g)

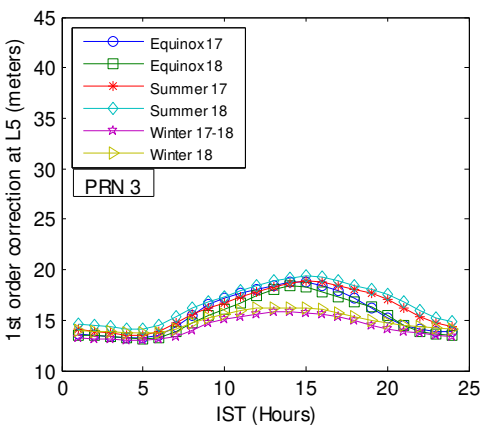

(b)

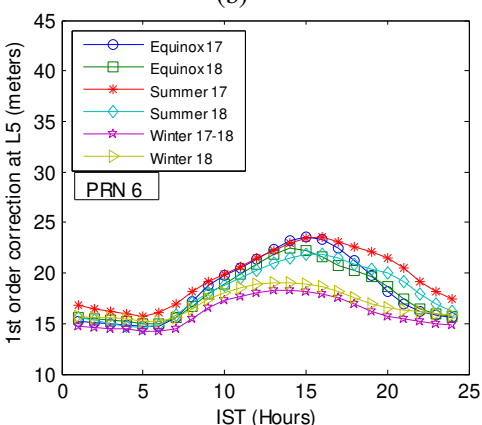

(e)

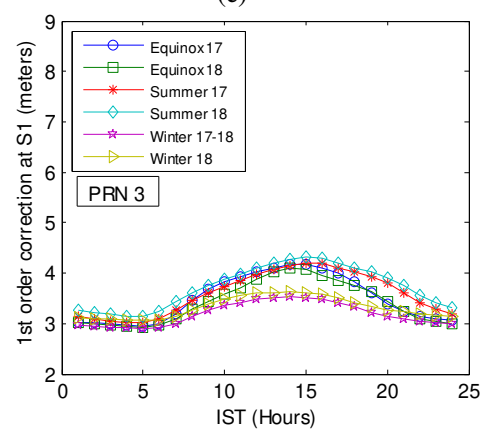

(h)

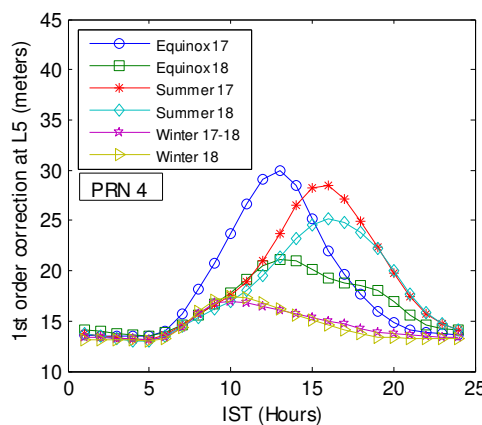

(c)

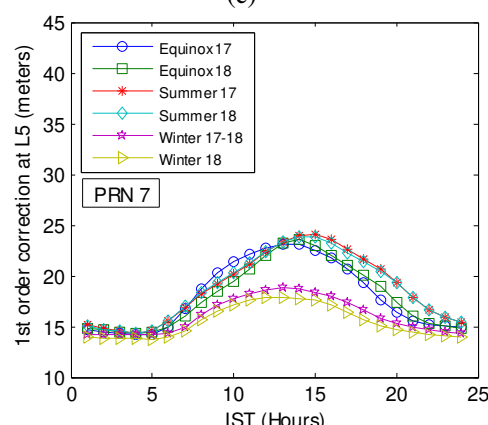

(f)

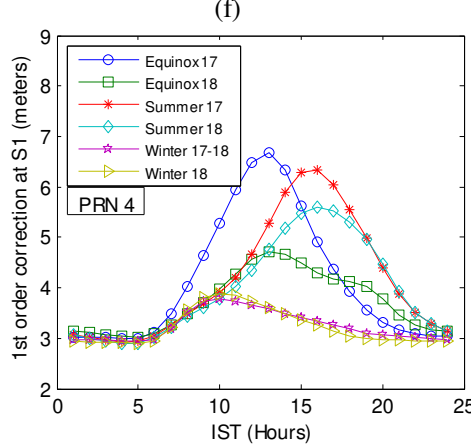

(i) 


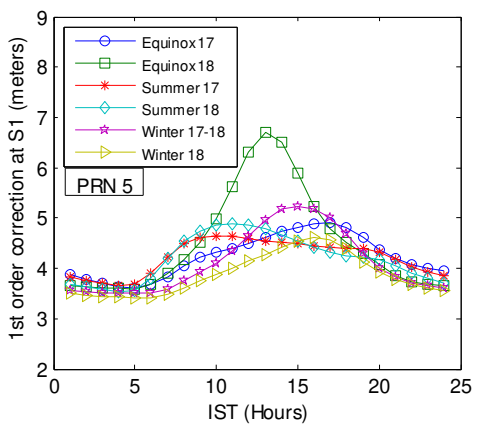

(j)

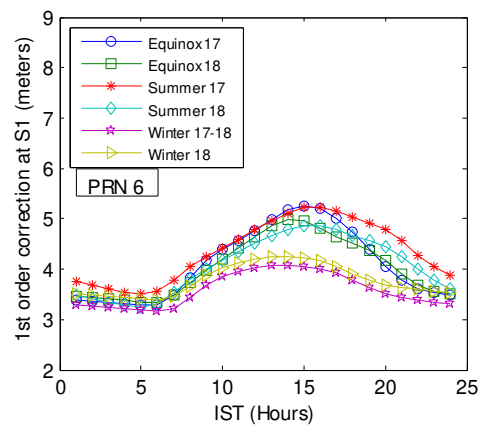

(k)

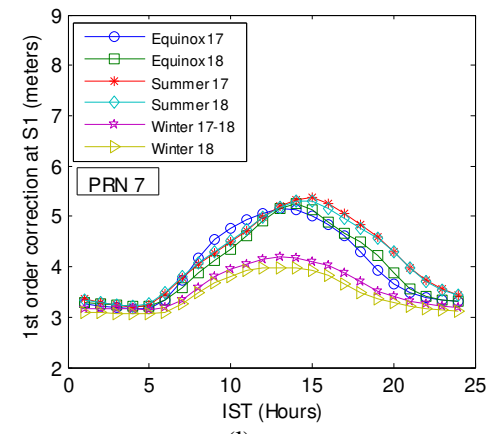

(1)

Fig.9 Seasonal Mean temporal variation of first-order ionospheric correction for PRN 2-7 during 2017-18

(a)-(f) at L5 frequency, (g)-(l) at S1 frequency

\section{References}

1. Bradford W. Parkinson (Stanford University, Stanford, C. ), \& James J. Spilker Jr. (Stanford Telecom, Sunnyvale, C. (2013). Global Positioning System: Theory and Applications (Vol. 53). https://doi.org/10.1017/CBO9781107415324.004

2. Bhardwaj, S. C., Shekhar, S., Vidyarthi, A., \& Prakash, R. (2020). Satellite Navigation and Sources of Errors in Positioning: A Review (pp. 43-50). Dehradun, India: IEEE. https://doi.org/10.1109/icaccm50413.2020.9212941

3. Hernández-Pajares, M., Juan, J. M., Sanz, J., Aragón-Àngel, À., García-Rigo, A., Salazar, D., \& Escudero, M. (2011). The ionosphere: Effects, GPS modeling and the benefits for space geodetic techniques. Journal of Geodesy, 85(12), 887-907. https://doi.org/10.1007/s00190-011-0508-5

4. Jakowski, N., Mayer, C., Hoque, M. M., \& Wilken, V. (2011). Total electron content models and their use in ionosphere monitoring. Radio Science, 46(5), 1-11. https://doi.org/10.1029/2010RS004620

5. Dow, J. M., Neilan, R. E., \& Rizos, C. (2009). The International GNSS Service in a changing landscape of Global Navigation Satellite Systems. Journal of Geodesy, 83(3-4), 191-198. https://doi.org/10.1007/s00190-008-0300-3

6. Suryanarayana Rao, K. N. (2007). GAGAN - The Indian satellite based augmentation system. Indian Journal of Radio and Space Physics, 36(4).

7. Sunda, S., Sridharan, R., Vyas, B. M., Khekale, P. V., Parikh, K. S., Ganeshan, A. S., ... Bagiya, M. S. (2015). Satellite-based augmentation systems: A novel and cost-effective tool for ionospheric and space weather studies. Space Weather, 13(1), 6-15. https://doi.org/10.1002/2014SW001103

8. Acharya, R., Nagori, N., Jain, N., Sunda, S., Regar, S., Sivaraman, M. R., \& Bandopadhyay, K. (2007). Ionospheric studies for the implementation of GAGAN. Indian Journal of Radio and Space Physics, 36(5), 394-404.

9. Shukla, A. K., Shinghal, P., Sivaraman, M. R., \& Bandyopadhyay, K. (2009). Comparative analysis of the effect of ionospheric delay on user position accuracy using single and dual frequency gps receivers over indian region. Indian Journal of Radio and Space Physics, 38(1), 57-61.

10. Venkata Ratnam, D., Sarma, A. D., Satya Srinivas, V., \& Sreelatha, P. (2011). Performance evaluation of selected ionospheric delay models during geomagnetic storm conditions in low-latitude region. Radio Science, 46(3), 4-9. https://doi.org/10.1029/2010RS004592

11. Sivavaraprasad, G., \& Venkata Ratnam, D. (2017). Performance evaluation of ionospheric time delay forecasting models using GPS observations at a low-latitude station. Advances in Space Research, 60(2), 475-490. https://doi.org/10.1016/j.asr.2017.01.031

12. Montenbruck, O., Steigenberger, P., \& Riley, S. (2015). IRNSS orbit determination and broadcast ephemeris assessment. Institute of Navigation International Technical Meeting 2015, ITM 2015, (c), 185-193.

13. Zaminpardaz, S., Teunissen, P. J. G., \& Nadarajah, N. (2016). IRNSS stand-alone positioning: first results in Australia. Journal of Spatial Science, 61(1), 5-27. https://doi.org/10.1080/14498596.2016.1142398

14. Mruthyunjaya, L., \& Ramasubramanian, R. (2017). IRNSS Signal in Space ICD for Standard Positioning System, Version1.1. Retrieved from http://www.isro.gov.in/irnss-programme/

15. Ayyagari, D., Chakraborty, S., Das, S., Shukla, A., Paul, A., \& Datta, A. (2020). Performance of NavIC for studying the ionosphere at an EIA region in India. Advances in Space Research, 65(6), 1544-1558. https://doi.org/10.1016/j.asr.2019.12.019 
16. Rethika \$, T., Mishra, S., Nirmala, S., Rathnakara, S. C., \& Ganeshan, A. S. (2013). Single frequency ionospheric error correction using coefficients generated from regional ionospheric data for IRNSS. Indian Journal of Radio \& Space Physics (Vol. 42).

17. Desai, M. V., \& Shah, S. N. (2018). The GIVE ionospheric delay correction approach to improve positional accuracy of NavIC/IRNSS single-frequency receiver. Current Science, 114(8), 1665-1676. https://doi.org/10.18520/cs/v114/i08/1665-1676

18. Desai, M. V., \& Shah, S. N. (2019). Estimation of ionospheric delay of NavIC/IRNSS signals using the Taylor Series Expansion. Journal of Space Weather and Space Climate, 9(I), A23. https://doi.org/10.1051/swsc/2019023

19. Sinha, S., Bhardwaj, S. C., Vidyarthi, A., Jassal, B. S., \& Shukla, A. K. (2019). Ionospheric Scintillation analysis using ROT and ROTI for Slip Cycle Detection. In 2019 4th International Conference on Information Systems and Computer Networks, ISCON 2019 (pp. 461-466). Institute of Electrical and Electronics Engineers Inc. https://doi.org/10.1109/ISCON47742.2019.9036215

20. Hager, B. H., King, R. W., \& Murray, M. H. (1991). System Global Positioning.

21. Bhardwaj, S. C., Vidyarthi, A., Jassal, B. S., \& Shukla, A. K. (2021). Investigation of ionospheric total electron content (tec) during summer months for ionosphere modeling in indian region using dualfrequency navic system. In Advances in Intelligent Systems and Computing (Vol. 1166, pp. 83-91). Springer. https://doi.org/10.1007/978-981-15-5148-2_8

22. Mannucci, A. J., Wilson, B. D., Yuan, D. N., Ho, C. H., Lindqwister, U. J., \& Runge, T. F. (1998). A global mapping technique for GPS-derived ionospheric total electron content measurements. Radio Science, 33(3), 565-582. https://doi.org/10.1029/97RS02707

23. COSTER, A. J., GAPOSCHKIN, E. M., \& THORNTON, L. E. (1992). Real- Time Ionospheric Monitoring System Using GPS. Navigation, 39(2), 191-204. https://doi.org/10.1002/j.21614296.1992.tb01874.x

24. Wilson, B. D., \& Mannucci, A. J. (1993). Instrumental Biases in Ionospheric Measurements Derived from GPS Data. Proceedings of the 6th International Technical Meeting of the Satellite Division of The Institute of Navigation (ION GPS 1993), 1343-1351.

25. Arikan, F., Nayir, H., Sezen, U., \& Arikan, O. (2008). Estimation of single station interfrequency receiver bias using GPS-TEC. Radio Science, 43(4), 1-13. https://doi.org/10.1029/2007RS003785

26. Sunehra, D. (2016). TEC and Instrumental Bias Estimation of GAGAN Station Using Kalman Filter and SCORE Algorithm. Positioning, 07(01), 41-50. https://doi.org/10.4236/pos.2016.71004

27. Zhang, D. H., Zhang, W., Li, Q., Shi, L. Q., Hao, Y. Q., \& Xiao, Z. (2010). Accuracy analysis of the GPS instrumental bias estimated from observations in middle and low latitudes. Annales Geophysicae, 28(8), 1571-1580. https://doi.org/10.5194/angeo-28-1571-2010

28. Maheshwari, M., Nirmala, S., Kavitha, S., \& Ratanakara, S. C. (2019). Kalman filter based estimation of differential hardware biases with triangular interpolation technique for IRNSS. Advances in Space Research, 63(2), 1051-1064. https://doi.org/10.1016/j.asr.2018.09.031

29. Siva Krishna, K., \& Ratnam, D. V. (2020). Determination of NavIC differential code biases using GPS and NavIC observations. Geodesy and Geodynamics, 11(2), 97-105. https://doi.org/10.1016/j.geog.2020.01.001

30. Bhardwaj, S. C., Vidyarthi, A., Jassal, B. S., \& Shukla, A. K. (2020). Estimation of Temporal Variability of Differential Instrumental Biases of NavIC Satellites and Receiver using Kalman Filter. Radio Science. https://doi.org/10.1029/2019RS006886

31. Jiang, H., Wang, Z., An, J., Liu, J., Wang, N., \& Li, H. (2018). Influence of spatial gradients on ionospheric mapping using thin layer models. GPS Solutions, 22(1). https://doi.org/10.1007/s10291017-0671-0

32. Sinha, S., Mathur, R., Bharadwaj, S. C., Vidyarthi, A., Jassal, B. S., \& Shukla, A. K. (2018). Estimation and smoothing of tec from navic dual frequency data. 2018 4th International Conference on Computing Communication and Automation, ICCCA 2018, 1-5. https://doi.org/10.1109/CCAA.2018.8777665

33. Li, J., \& Jin, S. (2016). Second-order ionospheric effects on ionospheric electron density estimation from GPS Radio Occultation. International Geoscience and Remote Sensing Symposium (IGARSS), 2016-Novem, 3952-3955. https://doi.org/10.1109/IGARSS.2016.7730027

34. Bhardwaj, S. C., Vidyarthi, A., Jassal, B. S., \& Shukla, A. K. (2018). Study of temporal variation of vertical TEC using NavIC data. In 2017 International Conference on Emerging Trends in Computing and Communication Technologies, ICETCCT 2017 (Vol. 2018-Janua, pp. 1-5). Institute of Electrical and Electronics Engineers Inc. https://doi.org/10.1109/ICETCCT.2017.8280317

35. Bharadwaj, S. C., \& Vidyarthi, A. (1990). Process of Detection, Determination and Correction Cycle S lip E rror : A Review.

36. Komjathy, A. (1997). Global Ionospheric Total Electron Content Mapping Using the Global Positioning System. Engineering. 
37. Bagiya, M. S., Joshi, H. P., Iyer, K. N., Aggarwal, M., Ravindran, S., \& Pathan, B. M. (2009). Annales Geophysicae TEC variations during low solar activity period ( 2005 - 2007 ) near the Equatorial Ionospheric Anomaly Crest region in India, 1047-1057.

38. Willmore, A. P. (1970). Electron and ion temperatures in the ionosphere. Space Science Reviews, 11(5), 607-670. https://doi.org/10.1007/bf00177027

39. Chauhan, V., Singh, O. P., \& Singh, B. (2011). Diurnal and seasonal variation of GPS-TEC during a low solar activity period as observed at a low latitude station Agra. Indian Journal of Radio and Space Physics, 40(1), 26-36.

40. Singh, A. K., Sardar, N., Rizvi, S., Rathore, S., \& Vijay, S. K. (2013). Nighttime enhancement of ionospheric parameters. Indian Journal of Radio and Space Physics, 42(4), 240-250. 
Figures

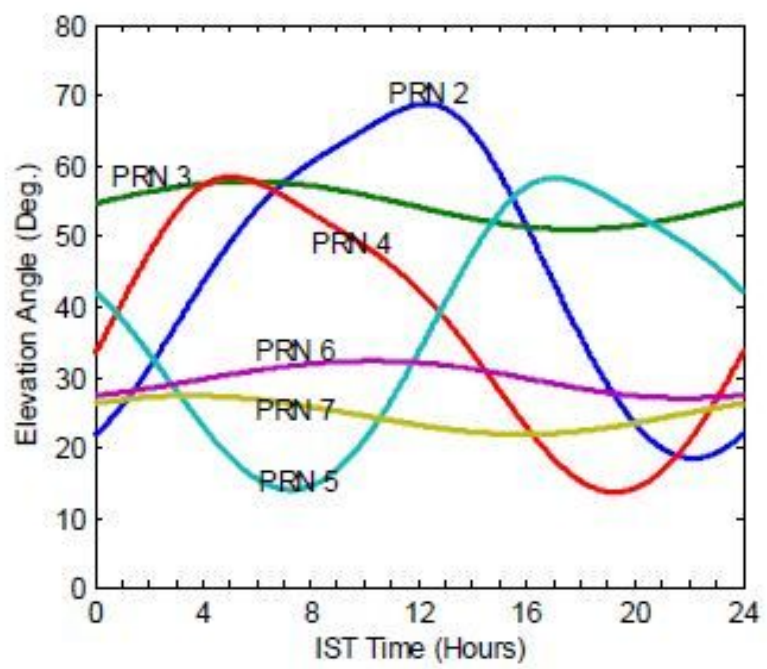

(a)

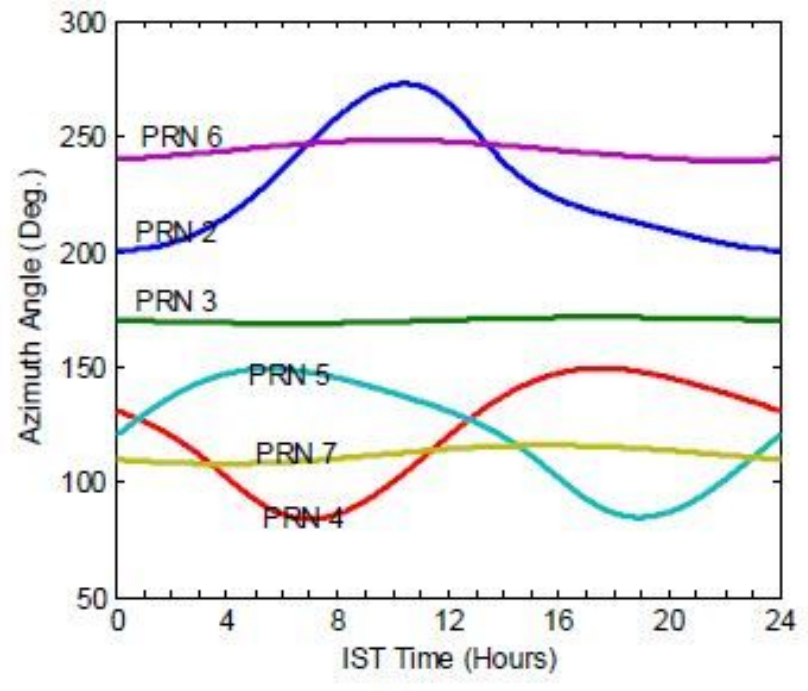

(b)

\section{Figure 1}

Diurnal (a) Elevation angle (b) Azimuth angle variation of Satellites PRN 2-7 on Jun. 5, 2017
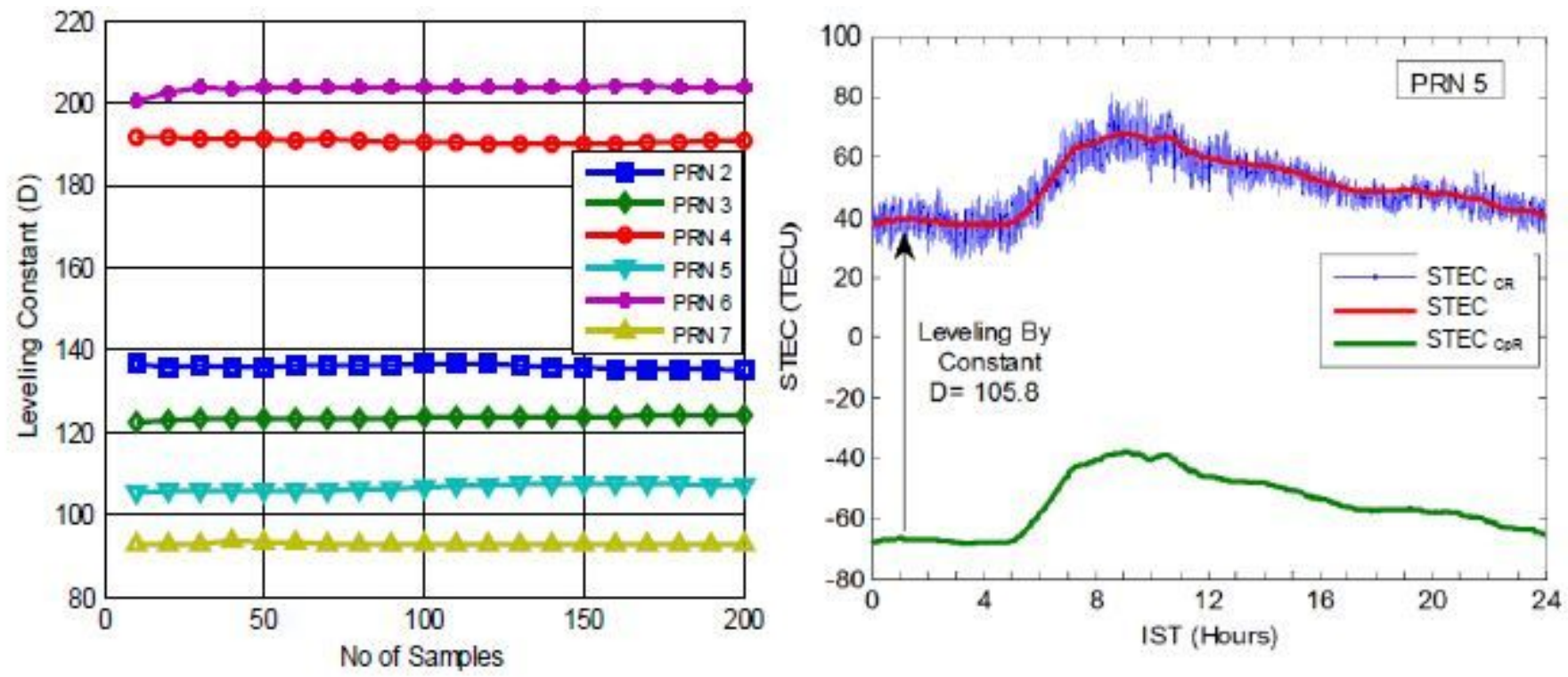

Figure 2

(a) Variation of Leveling Constant (b) Carrier smoothing of STEC measurement 

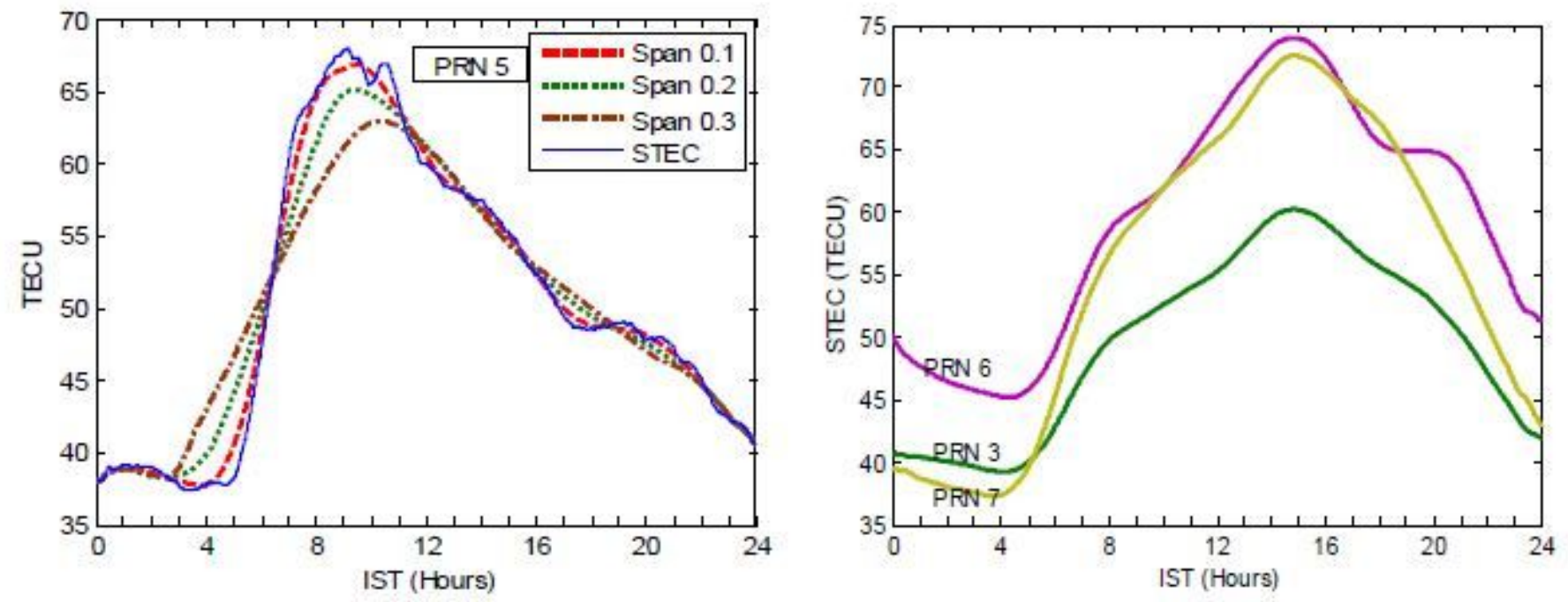

Figure 3

(a) Effect of moving average filter span on STEC smoothing (b) smoothen STEC of PRN 3, 6, and 7
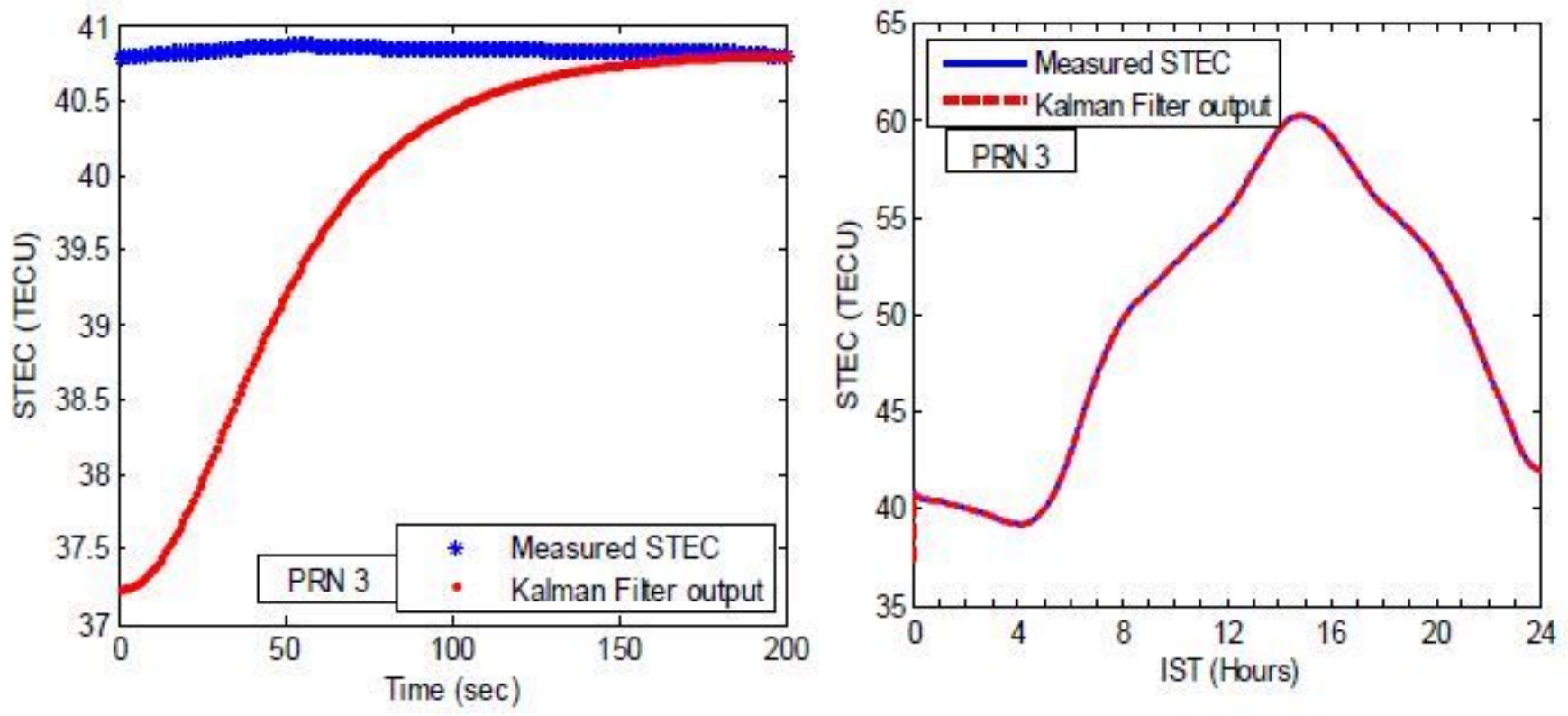

Figure 4

(a) Convergence and (b) Performance of Kalman filter 


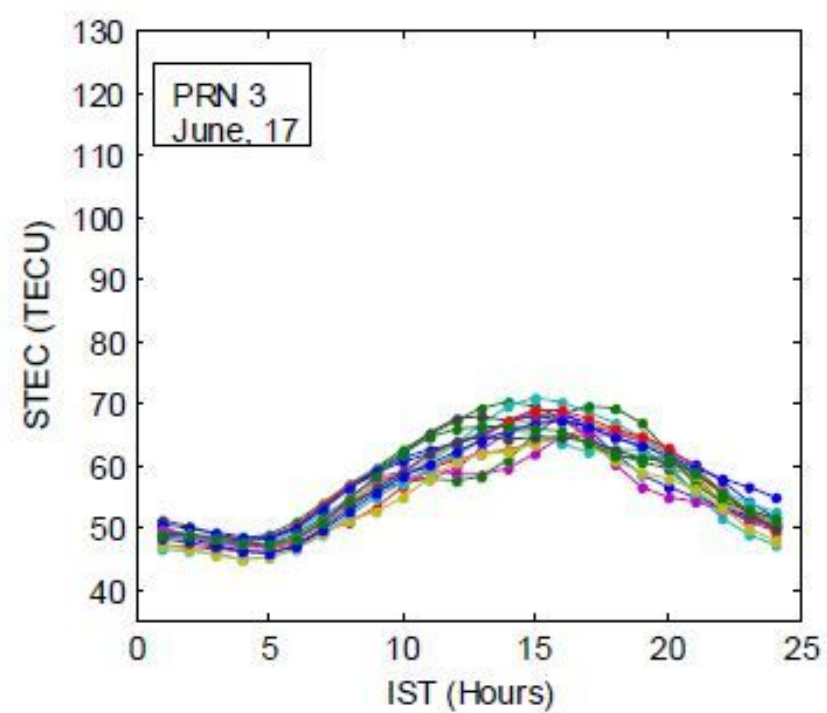

(a)

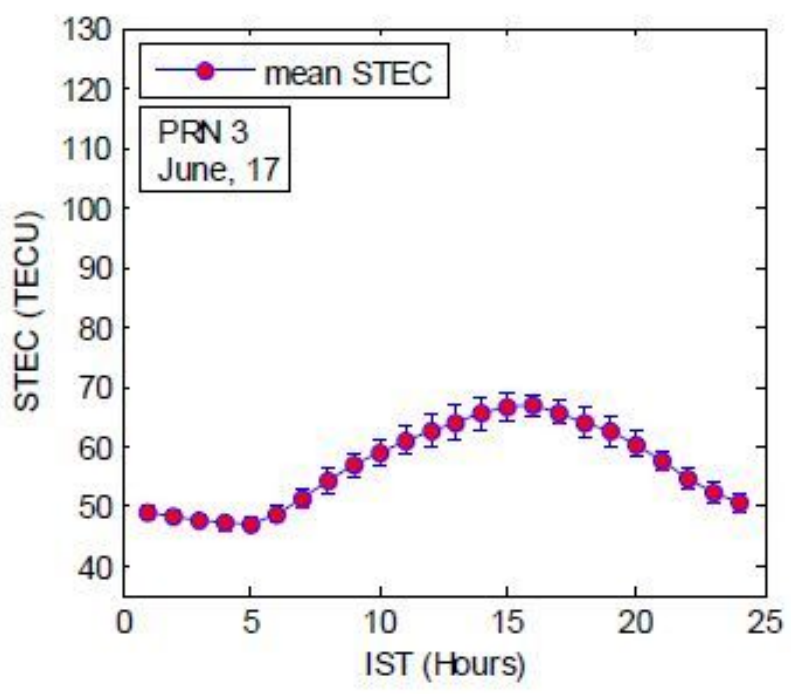

(b)

Figure 5

STEC in June 2017 for PRN 3 (a) Daily temporal variation (b) Mean monthly temporal variation 

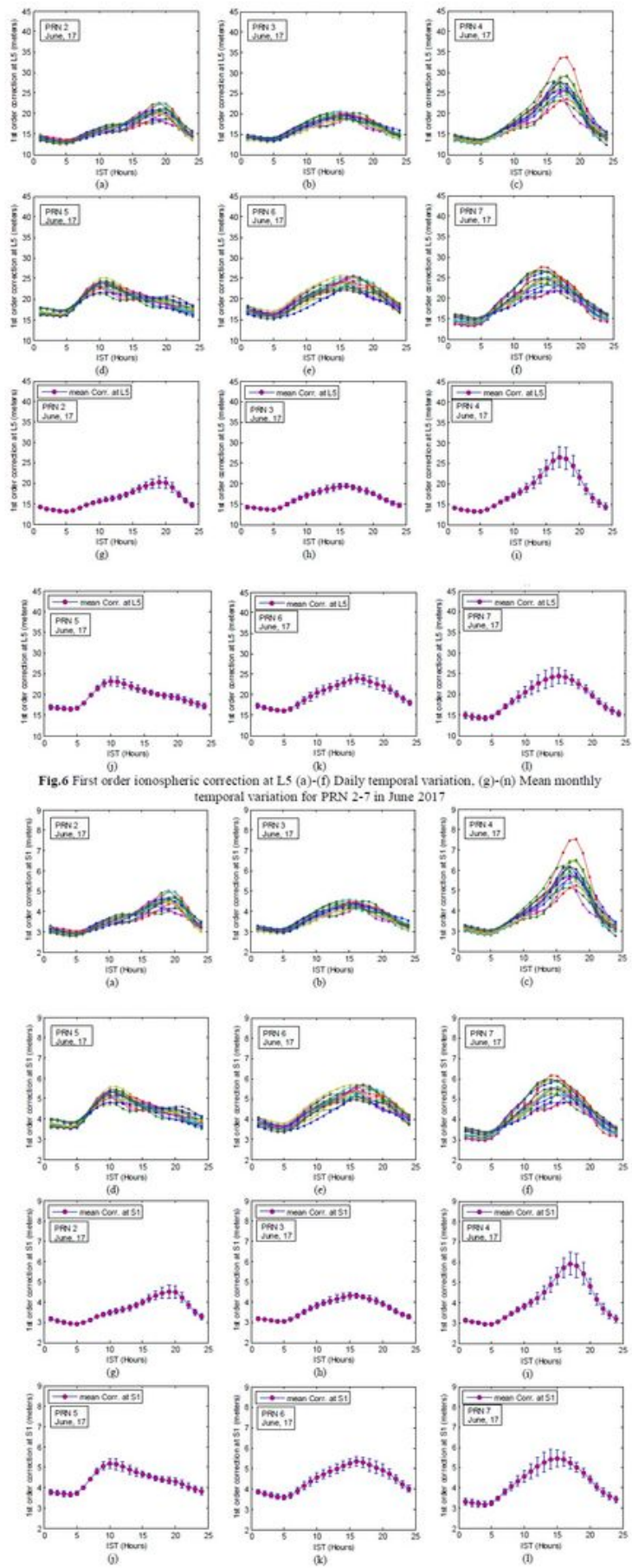

\section{Figure 6}

First order ionospheric correction at L5 (a)-(f) Daily temporal variation, (g)-(n) Mean monthly temporal variation for PRN 2-7 in June 2017 


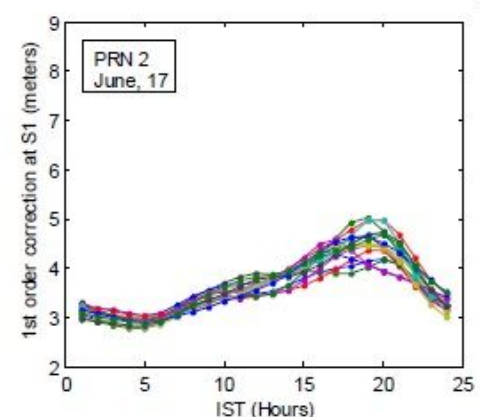

(a)

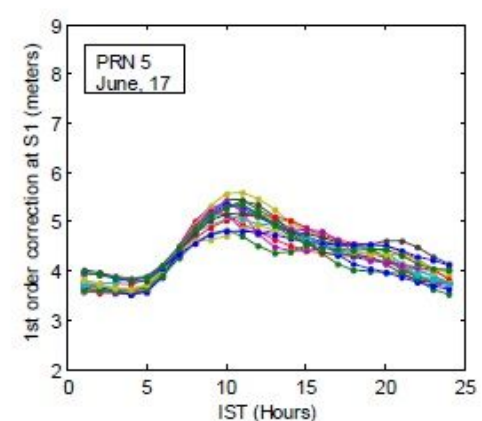

(d)

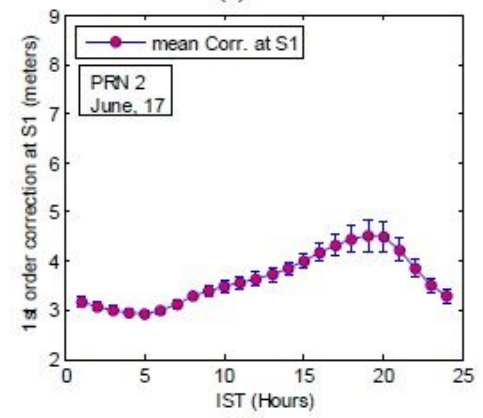

(g)

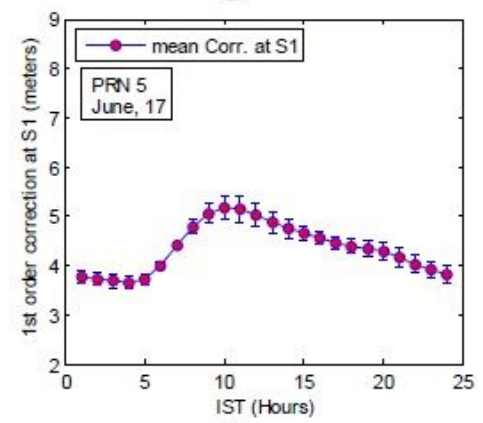

(j)

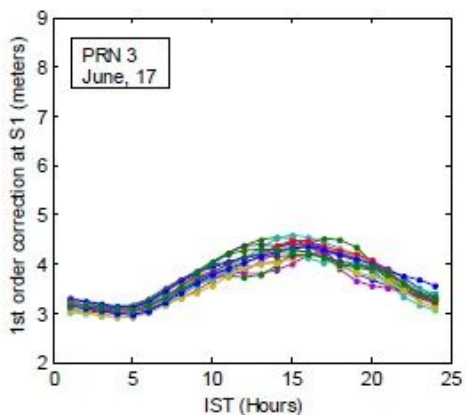

(b)

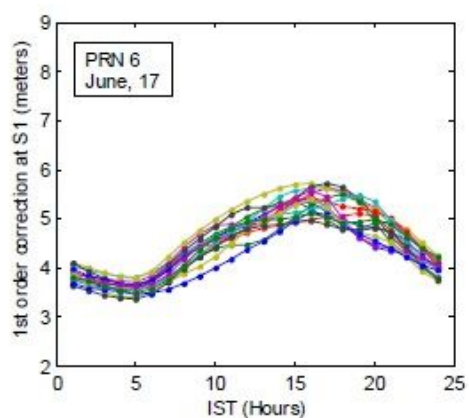

(e)

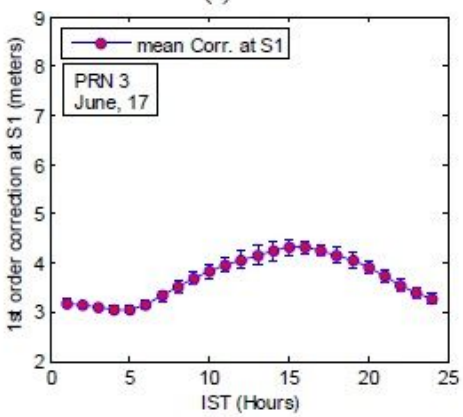

(h)

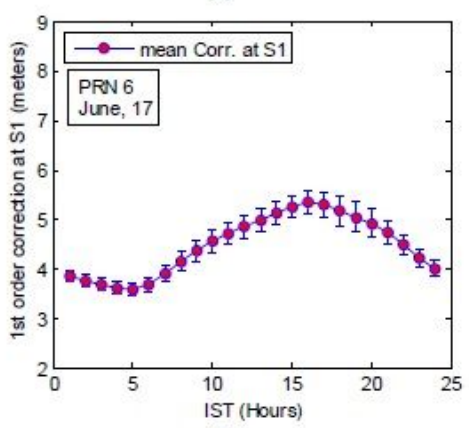

(k)

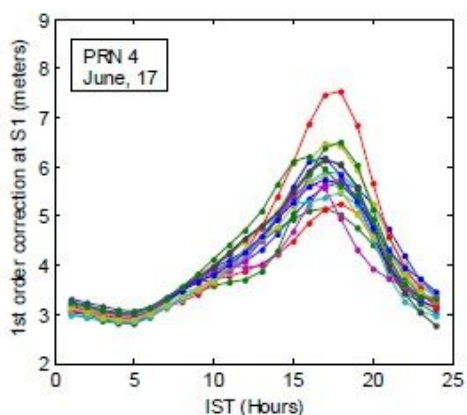

(c)

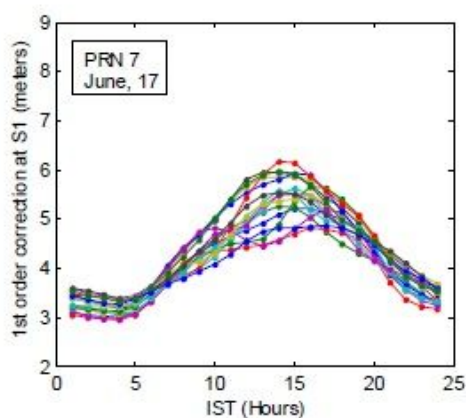

(f)

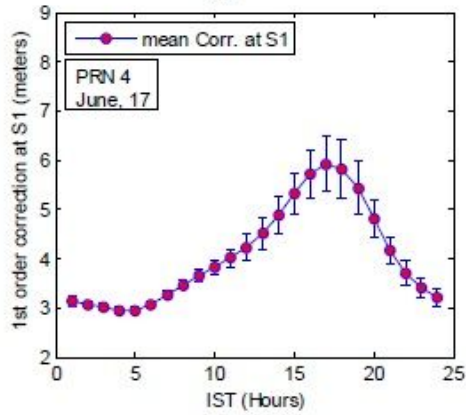

(i)

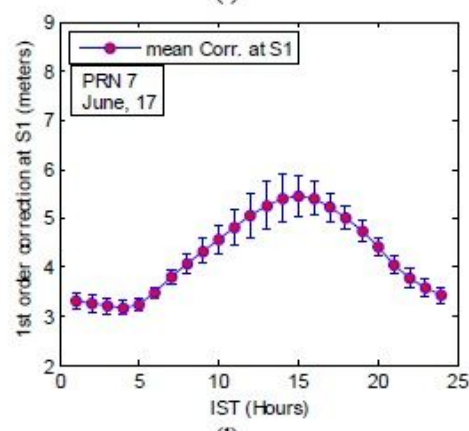

(1)

\section{Figure 7}

First order ionospheric correction at S1 (a)-(f) Daily temporal variation, (g)-(I) Monthly mean temporal variation for PRN 2-7 in June 2017 


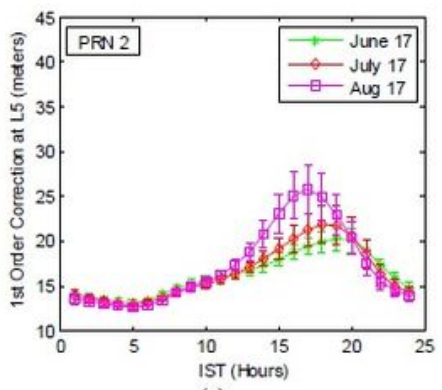

(a)

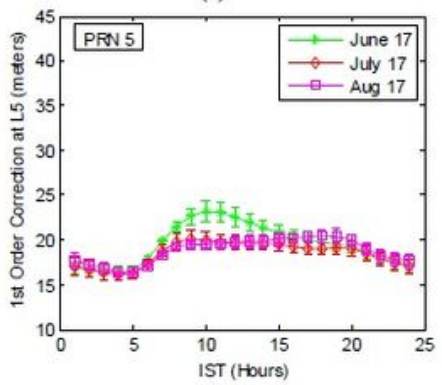

(d)

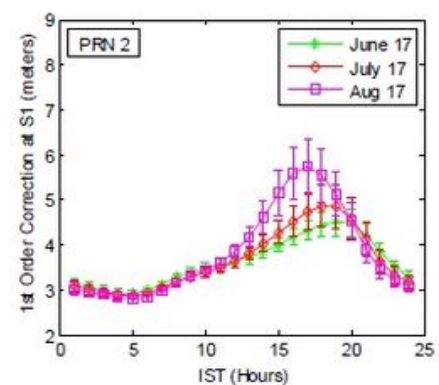

(g)

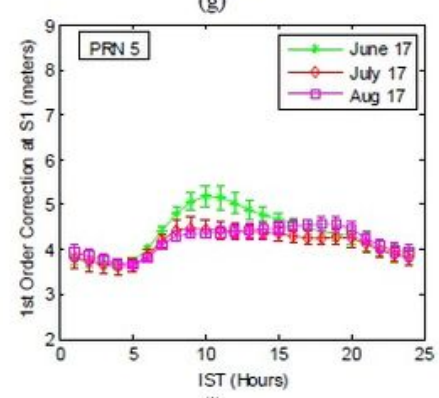

(j)

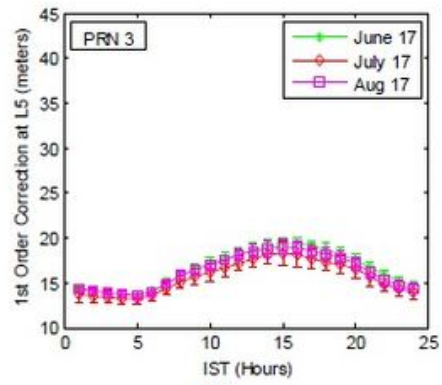

(b)

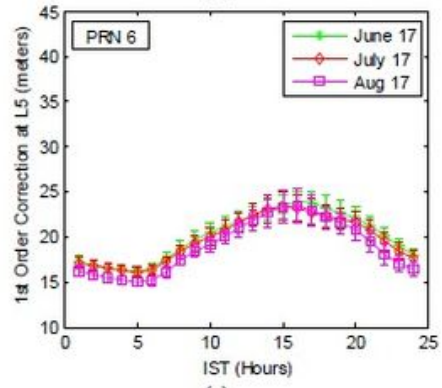

(e)

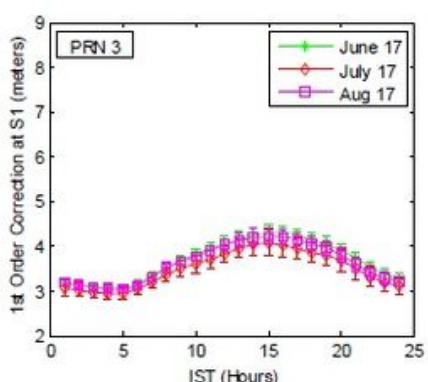

(h)

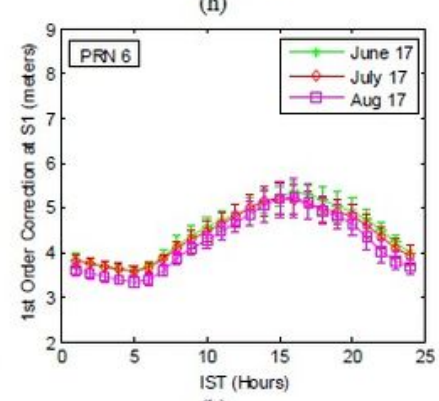

(k)

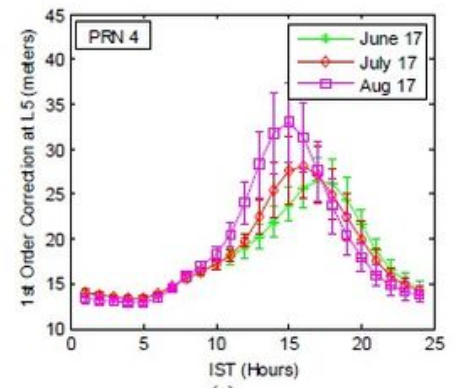

(c)

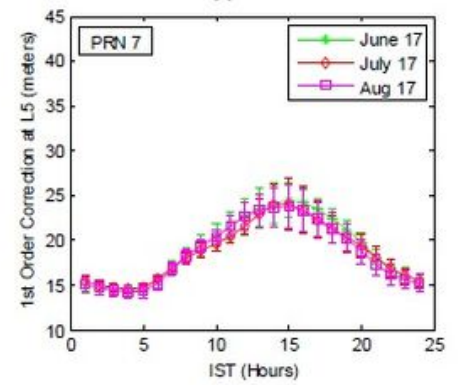

(f)

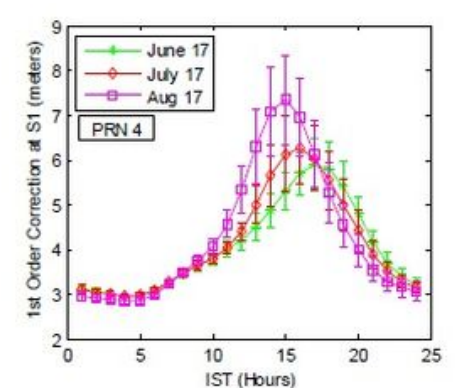

(i)

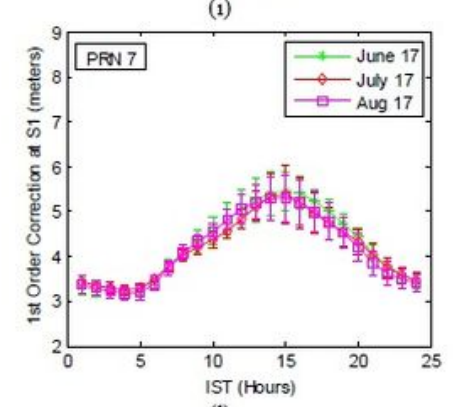

(1)

\section{Figure 8}

Monthly Mean temporal variation of first-order ionospheric correction for PRN 2-7 during summer season 2017 (a)-(f) at L5 frequency, (g)-(l) at S1 frequency 

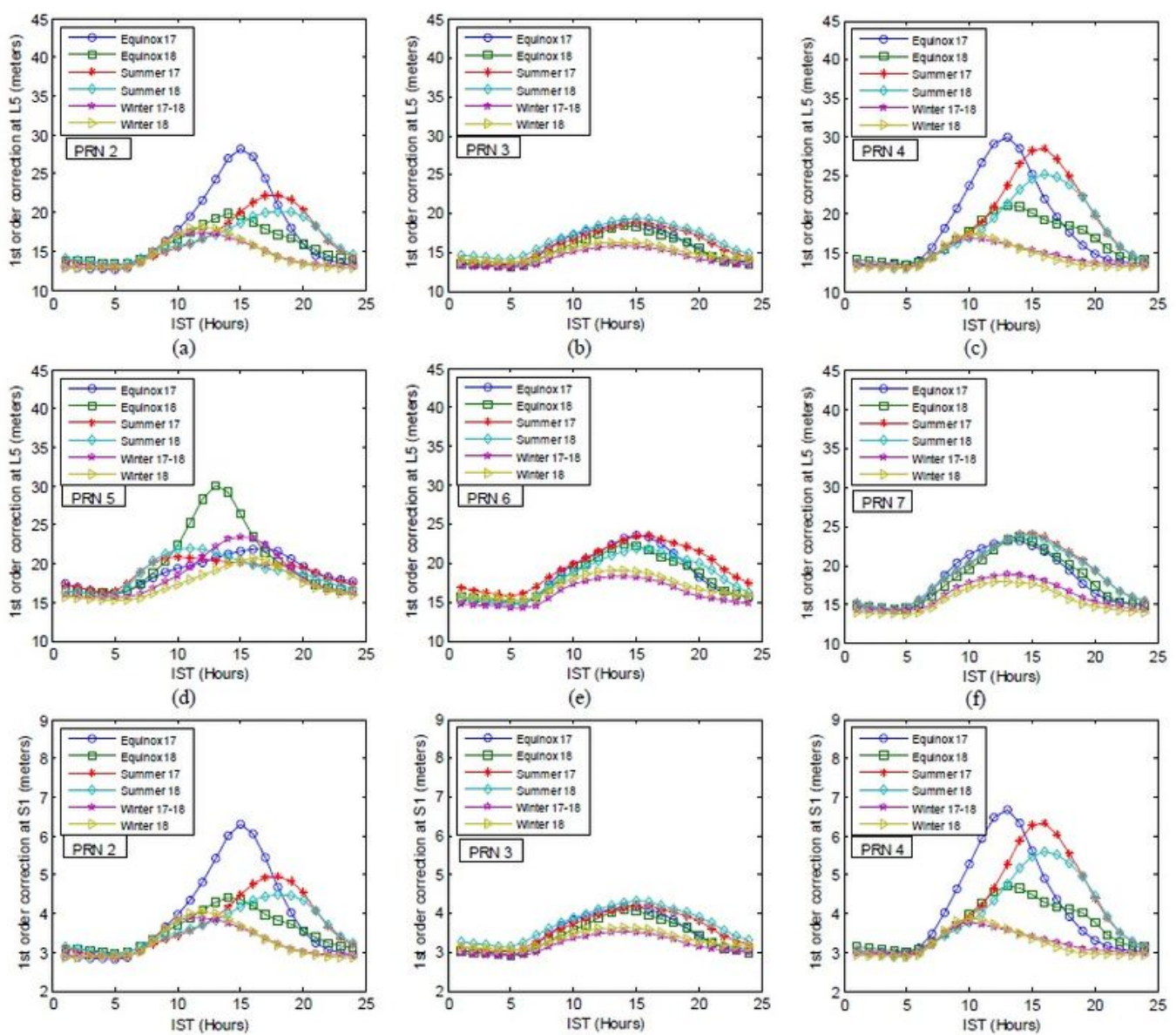

(g)

(h)

(i)
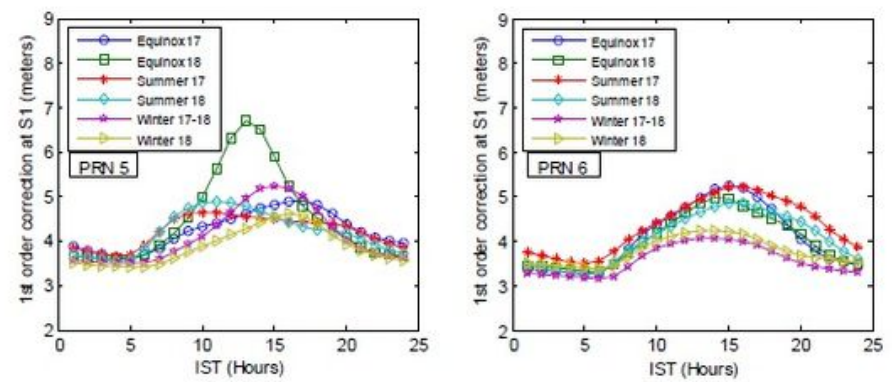

(k)

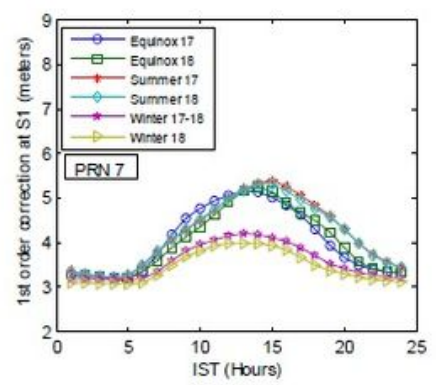

(1)

\section{Figure 9}

Seasonal Mean temporal variation of first-order ionospheric correction for PRN 2-7 during 2017-18 (a)-(f) at L5 frequency, (g)-(I) at S1 frequency 